\title{
ASPECTOS FLORÍSTICOS QUANTITATIVOS E COMPARATIVOS DA VEGETAÇÃO ARBÓREA DA RESERVA FLORESTAL DO SACAVÉM, SÃO LUÍS, MARANHÃO (BRASIL)
}

\author{
Francisca Helena MUNIZ'; Oswaldo CESAR²; Reinaldo MONTEIRO²
}

\begin{abstract}
RESUMO - Foi inventariado 0.5 ha de mata localizado na Reserva Florestal do Saciavém. pante

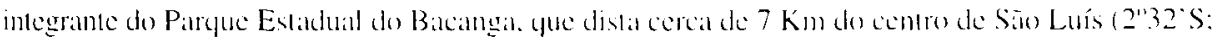

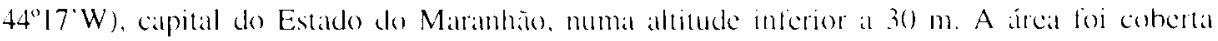
originalmente por uma lloresta tropical tumidit. denominada localmente de "Pré-Amaronia". O estudo foi realizado nas manchas remanescentes de vegetaçaio, dividido em 50 parcelas de $10 \times 10$ 17. Has qualis foram amostrados +10 individues com PAP (perimetro a alluta do peito a partir de $15 \mathrm{~cm}$. perencentes a 34 lamilas, 66 géneros e 110 espécies, além de 46 espécies arbóreas. pertencentes a 41 generos e 25 famílias, yue não loram inclúdis na analise yuantilativa. O DAP

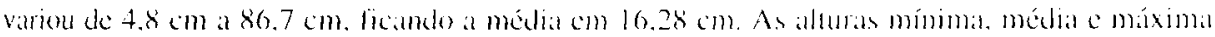
foram. respectivamente, $2.0 \mathrm{~m}, 11,16 \mathrm{~m}$ e $25,0 \mathrm{~m}$. Foram ketas comparaços com diversos trabalhos realizados na Amaronia. indicando yee a área estudada apresenta uma riquezal elevaldar, sendo comparivel alyuelas llorestas também em estrutura. embora os valores médios de altura e diâmetro scjam mais haixos.
\end{abstract}

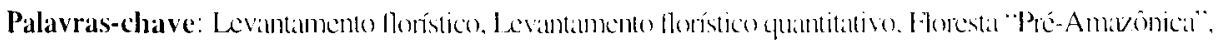
Reserva Florestal do Silliáén (Síno Luís-MA).

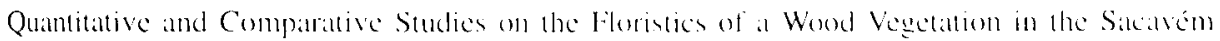
Forest Reserve - São Luís, State of Maramhion (Brabil)

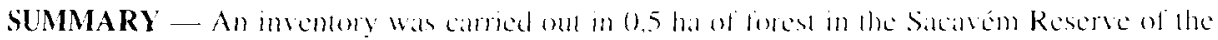

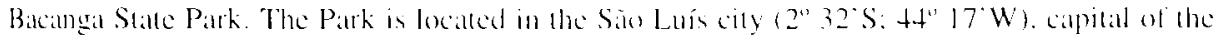

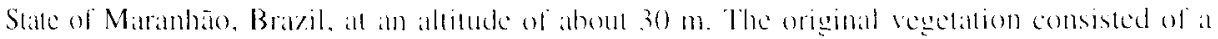

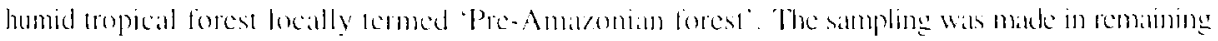

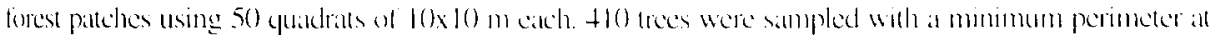

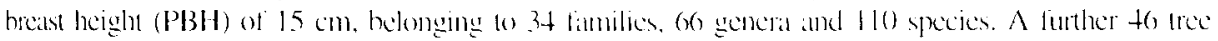
species distributed in 41 genera and 25 fandilies were aldo incluked hun occuming outside the sumpling anea

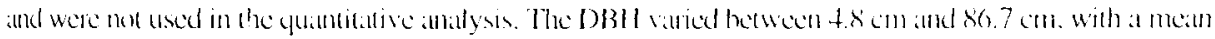
of $16.28 \mathrm{~cm}$. The minimum, mean and miximum heighes were $2.0 \mathrm{~m} .11 .6 \mathrm{~m}$ and $25.0 \mathrm{~m}$. respectively.

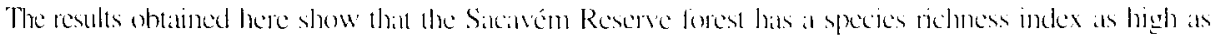

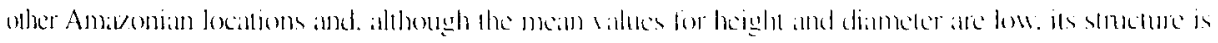
also similat wo the sereral studied sites of the sime vegetention.

Key-words: Floristic survey, Quantitative lloristic survey, Pre-Ama/nomian forest, Silcaném Reserve for(s) (Sin) Luís. Marnanhio).

\section{INTRODUÇÃO}

O Estado do Marambão ocupa uma área de $332.174 \mathrm{Km}^{2}$, com paisagens botanicas de aspectos delinidos, caraterizando diversals regiocs naturais (RIBEIRO, 1971). ABREL (1949) se referial al coste Estado como a titogeogratia que mais vivamente mostral as diferenças emtre o meio

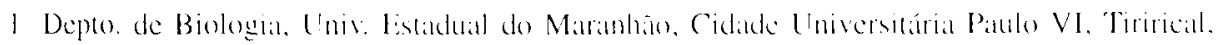
CEP $650000-000$. Silo l.uís. MA.

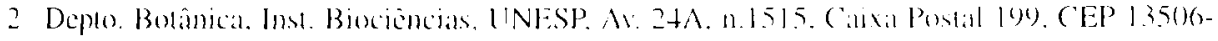
G(0), Rin Claro, SP. 
amazônico e as regiōes nordeste e central do Brasil, revelando a grande complexidade, heterogeneidade e o caráter transicional de suas formaçōess vegetais.

A ocorrencia da floresta amazônica no Maranhão é um fato bem conhecido. Entretanto, os limites desta área florestal denominada "Amazônia Maranhense" não foram ainda bem definidos. Até 1950, vários autores propuseram limites radicalmente diferentes paral a Amazônia. DUCKE \& BLACK (1954) discutiram detalhadamente os limites para algumas regioes. No mesmo ano SOARES (1953), usando fotos aéreas, estudos de campo e uma extensa bibliografia, apresentou uma obra quase completal sobre os limites sul e leste da Amazonia. FRÓES (1953) estimou que a área de ocorrência da floresta amazônica no Maranhão eră de $150.850 \mathrm{Km}^{2}$. cerca de $46 \%$ da área do Estado, incluída a llha de São Luís, com uma área de $8.57 \mathrm{Km}^{2}$.

A Illha de Sĩo Luís (2032’s, $44^{\circ} 17^{\circ} \mathrm{W}$ ), com uma áreal de $905 \mathrm{Km}^{2}$, está localizada no extremo norte do Estado e ocupa o centro do "Golfĩo Maranhense", faixa litorâneal que ocupa o grande recorte formado pelo afogamento dos estuários dos Rios Pindaré, Mearim e Itapecuru. separando as Baras de Sáno Marcose São José de Ribamar. É percorrida pelos Rios Bacangal Anil, que representam verdadeiros braços de mar. devido à grande influência da agua salgada que recebem. e por pequenos cursos de águla doce. que também estão sujeitos à ação periódica das marés (Fig. 1). A vegetação é classificada como secundária latifoliadil. caracterizada pelo grande número de embaúbas (Cecropia spp.) e lacres (Vismia spp.), ocorrendo no interior da ilha uma vegetação mista com a presença de babaçuais (Orbignna phaterata Mart.) (BRASIL-RADAM, 1973).

A Reserva Florestal do Sacavém. parte integrante do Parque Estadual do Bacanga, criado pelo Decreto Estadual n-7.545 de 02 de Março de 1980). apresenta uma área de 3.06 .5 ha, e tem um papel importante na preservação de mananciais de água gue, por um lado abastecem parte da população de São Luís (cerca de 20\% da demanda total de agua para abastecimento da cidade está sob a responsabilidade do Sistema Sacavém. da Companhia de água e Esgoto do Maranháo) e. por outro, contribuem parat os principalis alluentes do Rio Bacanga.

O rápido e desordenado crescimento do Estado e, principalmente do municipio de São Luís, vem calusando grandes alteraçẽes nal vegetação nativa. e em particular na Reserva Florestal do Sacavém. onde os constantes desmatamentos, as retiradas de barro e piçarra e a ocupação populacional, calusium sérios danos à mata c ao equilibrio ambiental de toda a Ilha. O processo de devastiçãón foi tão alcentuado (que, attualmente, at institucionalização) do Partuce pelo Governo do Estado, através da Secretaria de Estado do Meio Ambientec Turismo - SEMATUR (1992), implicou na redução da área, por força da exclusão das zonas (xupadas e julgadas impraticáveis para a rectuperação.

Apesar disso, ainda é possível 
encontrar na Reserva áreas de mata, com fauna e flora típicas não encontradas em outros ecossistemas da Ilha, o que as tornam áreas de refúgio de importância prioritária para serem preservadas permanentemente.

$O$ presente trabalho foi conduzido com o propósito de fornecer dados sobre a composição florística e a estrutura da vegetação da Reserva Florestal do Sacavém. esperando-se estabelecer subsídios que possam ser usados no controle ou como atenuantes das perturbações resultantes de sua exploração.

\section{MATERIAL E MÉTODOS}

\section{Caracterização da área}

O Parque Estadual do Bacanga, com uma extensão de 3.065 ha, ocupa a área centro-oeste da Ilha de São Luís e parte da zona central do município de mesmo nome, capital do Estado do Maranhão. Geograficamente, localiza-se próximo à linha do Equador, a aproximadamente $2^{\circ} 33^{\prime} \mathrm{S}$ e $44^{\circ} 14^{\prime} \mathrm{W}$, estando confinado entre
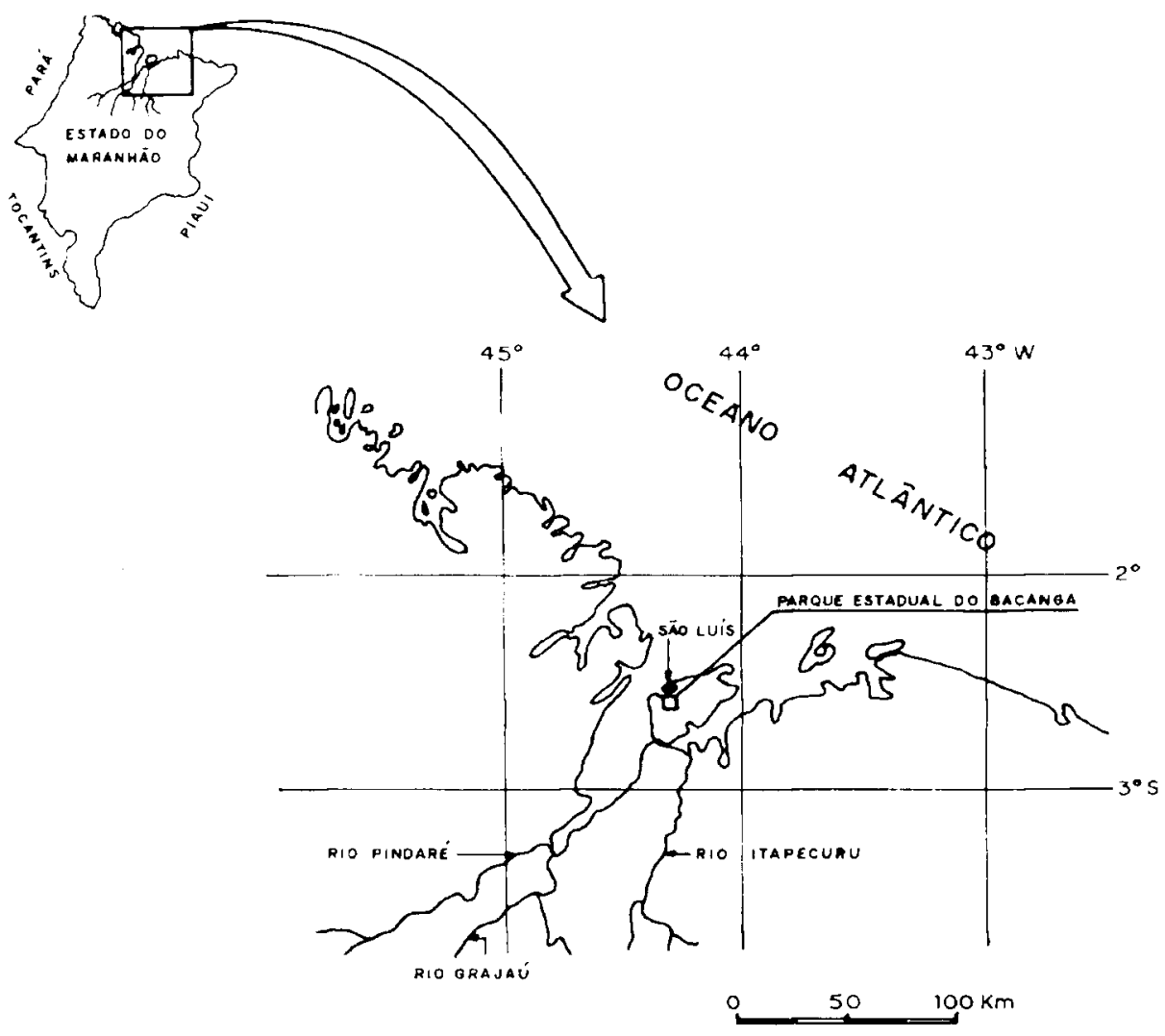

Figura 1. Localização da llha de São Luís no Estado do Maranhão, mostrando o Parque Estadual do Bacanga. 
zonas de forte pressão demográfica e o Distrito Industrial (Fig. 2). A Reserva Florestal do Sacavém, onde foi realizado este trabalho, está incluída no Parque Estadual do Bacanga, localizada a aproximadamente $7 \mathrm{Km}$ a SE do centro de São Luís, em uma planície com altitude inferior a $30 \mathrm{~m}$ (GOMES, 1991).

A área foi coberta originalmente por uma floresta tropical úmida, que hoje está restrita a pequenas manchas com poucos hectares em tamanho, separadas por floresta secundária. Essas áreas de floresta primária suportam uma alta biomassa com grandes árvores que podem alcançar até $30 \mathrm{~m}$ de altura, sendo a área basal dos troncos com DAP maior que 30 $\mathrm{cm}$, aproximadamente $29 \mathrm{~m} 2 / \mathrm{ha}$ (PIRES, 1983 apud HENRIQUES \& SOUSA, (1989).

FERREIRA (1992) dividiu o Parque em dois setores, com base no estado de conservação da vegetação. Dessa forma, o Setor A ("área da Reserva") corresponde a aproximadamente $1 / 3$ da área atual do Parque, e é composto de uma formação contínua da floresta PréAmazônica, predominantemente arbórea, apresentando no seu conjunto estágios diferenciados de preservação. Em certos trechos as árvores apresentam entre $25 \mathrm{~m}$ a $30 \mathrm{~m}$ de altura, chegando a mais de $100 \mathrm{~cm}$ de DAP, com um sub-bosque esparso e úmido, onde a penetração de luz é razoável. Em outros, as árvores são mais baixas ( $6 \mathrm{~m}$ a $10 \mathrm{~m}$ de altura) com DAP variando entre $5 \mathrm{~cm}$ e 15 $\mathrm{cm}$, com áreass em regeneração, sendo que a intensidade de luz nessas áreas é maior. Há ainda locais onde se verificam áreas com perturbação mais recente.

Este setor apresenta dois conjuntos florísticos distintos: uma área periodicamente alagada, cortada por um riacho perene que, pelas características do terreno, mais baixo e plano que nas áreas adjacentes, está sujeita à ação da cheia que ocorre durante o período de chuvas e que se assemelha a uma vegetação de várzea, com um grupo de espécies característico como anani (Symphonia globulifera L. f.), andiroba (Carapa guianensis Aubl.), juçara (Euterpe oleracea Mart.), buriti (Mauritia flexuosa L. f.) e babaçu (Orbygnia phalerata Mart.), além de espécimes de Musaceae e Araceae, entre outras; e a mata de terra firme, que apresenta variações quanto à fisionomia ao longo de sua área, mas sem a presença, ou pelo menos com uma ocorrência discreta, das espécies da área alagada. São espécies abundantes nesta segunda área o faveiro (Parkia pendula Benth.), o cumaru (Dipteryx lactmifera Ducke), o jatobá (Hymenaéa courbaril L.), a janaúba (Himathanthus articulatus (Vahl.) Woodson), o bacuri (Platonia insignis Mart.) e o jaborandi (Pilocarpus sp.), entre outras.

O segundo setor ("área do Parque") corresponde à toda a extensão do Parque que tem sofrido uma interferência antrópica contínua e diversificada, descaracterizando por completo a vegetação em relação à formação primitiva. A fisionomia da área, com algumas pequenas exceções, é de um campo abandonado com arbustos e subarbustos. 


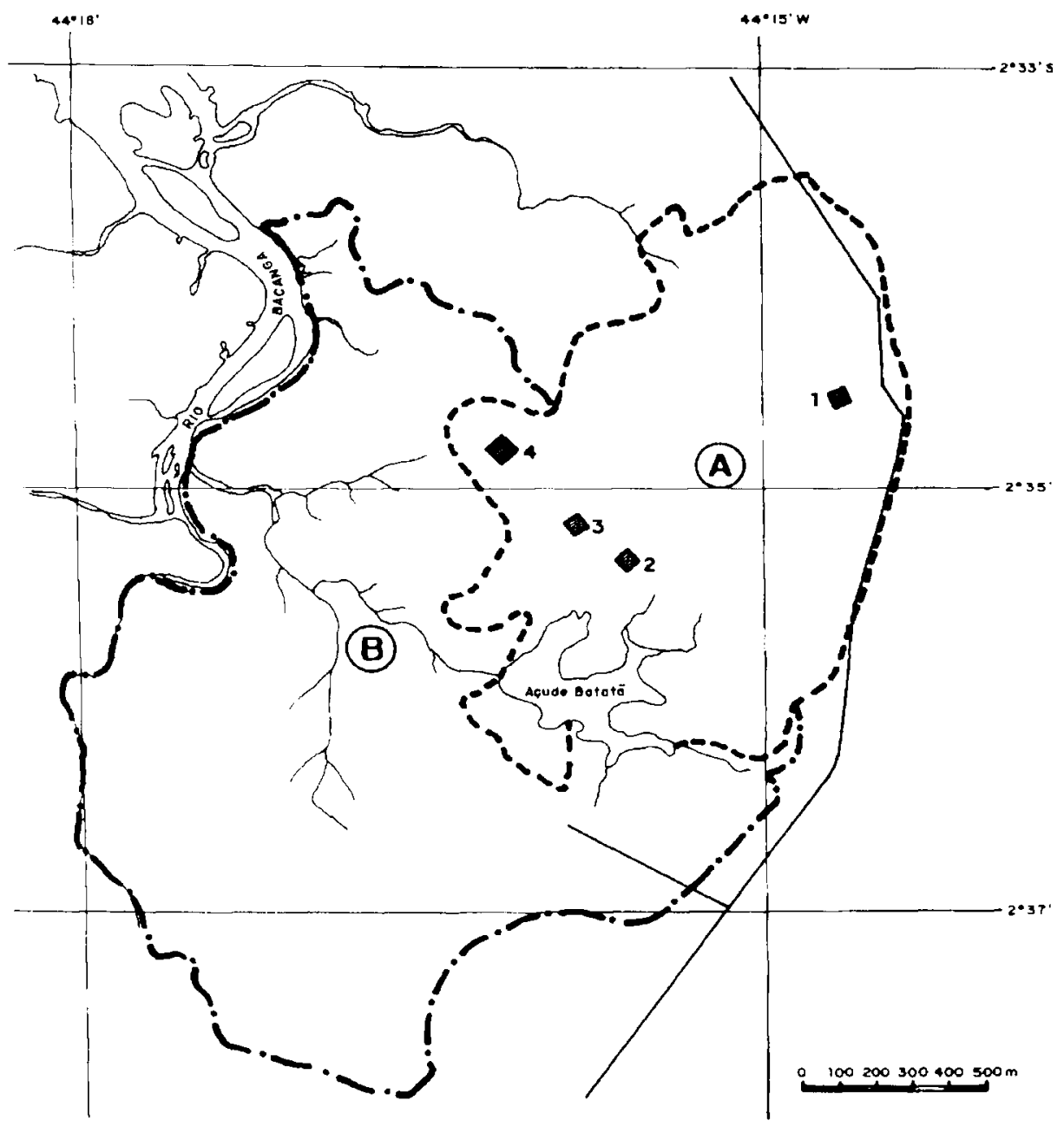

Figura 2. Parque Estadual do Bacanga, São Luís - MA, mostrando a área da Reserva Florestal do Sacavém c os locais de amostragem. A - área da Reserva; B - árca do Parque; 1, 2, 3, 4 áreas de estudo.

Adotando a classificação climática de Köppen, a Ilha de São Luís está incluída no tipo AW', com duas estações perfeitamente distintas: a chuvosa, no verão e se prolongando pelo outono, ocorrendo nesta estação do ano as maiores precipitações, e a seca, de julho a dezembro, registrando-se em setembro ou outubro as menores precipitações. As temperaturas médias se mantêm mais ou menos constantes durante o ano, com valores muito elevados, em tomo de $26^{\circ} \mathrm{C}$, sendo a amplitude térmica anual sempre inferior a $5^{\circ} \mathrm{C}$ (GUERRA, 1955).

O balanço hídrico (Fig. 3), elaborado a partir de dados de vinte anos de observação (1974 a 1993), acusa a presença de um período onde há excesso de água no solo (janeiro a junho) e, um outro, onde há deficiência (julho a 
dezembro). Decompondo a pluviosidade entre esses dois períodos, percebe-se que $87,40 \%$ das chuvas caem no primeiro semestre do ano, com aproximadamente 121 dias de chuva $(79,7 \%)$ e, tão somente $19,8 \%$ no restante do ano, em 30 dias com precipitação. aluviação. As formações do Grupo Barreiras dominam geologicamente quase que a totalidade da área do Parque, embora grandes extensōes já tenham sido destruídas por agentes modeladores, dando origem a vales e a pequenas depressões (SEMATUR, 1992).

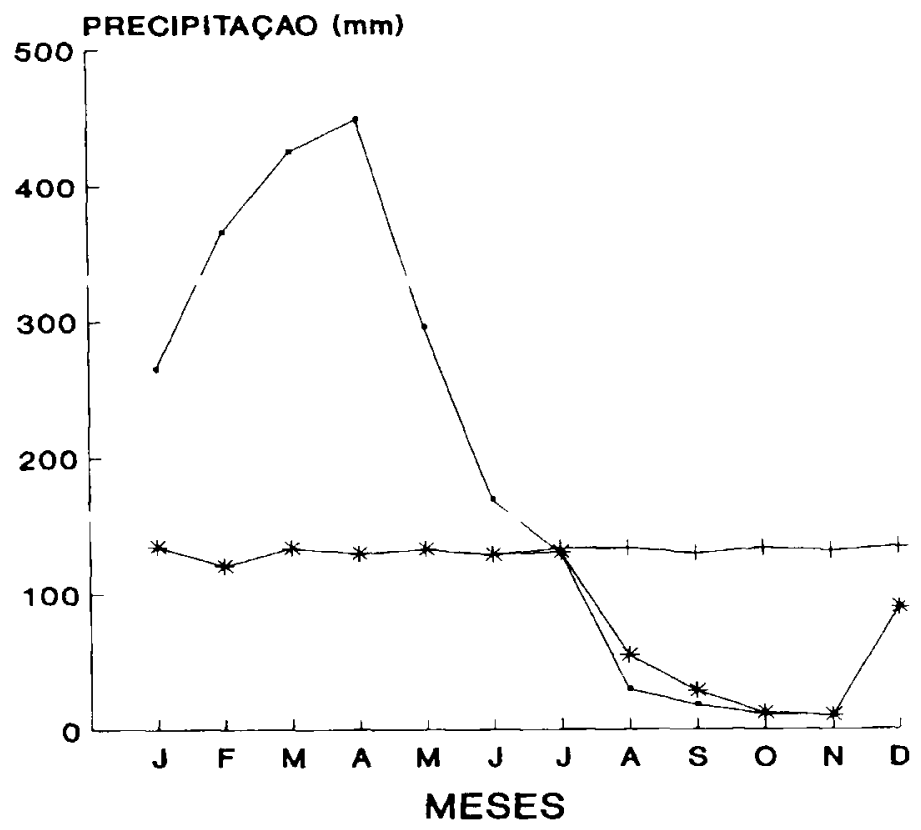

- Precipitaçao $(\mathrm{mm}) \longrightarrow$ ETP * ETR

Figura 3. Balanço Hídrico da llha de São Luís - MA, para o periodo de 1973-1992, de acordo com THORNTHWAITH \& MATHER (1955 (pmed MOTA, 1986), considerando a capacidade de armazenamento do solo de $100 \mathrm{~mm}$. Fonte: Estaçāo Meteorológica do Itapiracó (2" 32 'S: 44"18'W; $50,7 \mathrm{~m}$ de altitude). Precipitação - 2257mm; ETP - evapotranspiração potencial: ETR - evapotranspiração real; déficil hídrico $(473 \mathrm{~mm})$; execedente hídrico (1148mm).

A área do Parque ocupa o topo de pequena extensão da bacia sedimentar de São Luís. Apresenta uma caracterização geológica constituída de rochas sedimentares, basicamente representadas por arenitos e argilitos inconsolidados, de idade terciária, bastante alterados por
$O$ baixo desenvolvimento pedológico dos solos da Reserva Florestal do Sacavém reflete no comportamento físico e químico. devido ao fato dos mesmos serem essencialmente lateríticos, originários da meteorização do material sedimentar existente na área. Quando 
da presença de solo, este é formado por um ou dois horizontes de pequena espessura, variando de poucos centímetros. Sua composição é dominada pela fração areia, com baixa concentração de matéria orgânica.

Esses solos, denominados de "podsolos" (SEMATUR, 1992) apresentam coloração escura e são deficitários em relação à fertilidade. Apresentam baixa saturação de bases, moderada capacidade de troca de cátions, baixos teores de $\mathrm{Ca}^{++} \mathrm{e} \mathrm{K}^{+} \mathrm{e}$ valores de $\mathrm{Mg}^{++}$e $\mathrm{Al}^{+++}$variando de médios a altos.

\section{MÉTODOS}

O levantamento florístico foi realizado utilizando-se o método de parcelas (BRAUN-BLANQUET, 1979). Foram estabelecidas, em 4 áreas não contíguas no interior da mata de terra firme, 50 parcelas de $10 \times 10 \mathrm{~m}$, totalizando 5.000 m2 (Fig. 2).

Em cada uma das parcelas foram considerados os indivíduos lenhosos que apresentaram no mínimo $15 \mathrm{~cm}$ de perímetro à altura do peito (PAP) $(1,30 \mathrm{~m}$ do solo). Todos os indivíduos foram etiquetados e tiveram sua altura estimada, tomando-se como referência uma vara de coleta, marcada de metro em metro, com $12 \mathrm{~m}$ de comprimento total.

De cada indivíduo amostrado foi feita a coleta do material botânico, reprodutivo e/ou vegetativo, durante o período de janeiro/92 a junho/93, o qual foi identificado e depositado no Herbário (HRCB) do Instituto de Biociências de Rio Claro-UNESP e duplicatas no Herbário da Universidade Estadual do Maranhão. Além dos indivíduos etiquetados, foi coletado material botânico de todas as árvores em floração ou frutificação durante o período de estudo.

A diversidade florística foi estimada através do índice de Shannon e Weaver $\left(\mathrm{H}^{\prime}\right)$, segundo MUELLER-DOMBOIS \& ELLENBERG (1974).

A nomenclatura utilizada para a denominação das famílias segue o sistema de classificação de CRONQUIST (1981), exceto para a família Leguminosae, cuja nomenclatura segue o sistema de FNGLER (1964).

É apresentada, em histogramas, a distribuição de frequiência das classes de diâmetro das árvores de toda a fitocenose e, das espécies com pelo menos 10 indivíduos. A amplitude de classe de diâmetro foi fixada em $10 \mathrm{~cm}$, para que houvesse concordância com outros trabalhos publicados sobre o assunto.

Para a avaliação da distribuição dos diâmetros calculou-se o quociente "q", sugerido por Liocourt (1898 apud MEYER, 1952), obtido pela divisão do número de indivíduos de uma classe pelo número de indivíduos da classe anterior.

Com o objetivo de se verificar a presença ou não de estratificação, elaborouse o histograma de freqüência de classes de altura, com intervalo de $2 \mathrm{~m}$, utilizandose os valores de altura das copas.

\section{RESULTADOS}

\section{Composição Florística Quantitativa}

Foram amostrados, nas 50 parcelas demarcadas, 410 indivíduos vivos distribuídos em 34 famílias, 66 
gêneros e 88 espécies (além de 16 indeterminadas), e 5 mortos em pé, que foram anotados como um único grupo, sem distinção de espécie, não sendo considerados na análise quantitativa.

A Tabela 1 apresenta a lista, por família, das espécies encontradas no estudo florístico, acrescida de 46 espécies, pertencentes a 41 gêneros e 25 famílias, coletadas em caminhadas aleatórias fora da área de amostragem quantitativa.
A Figura 4 mostra que são necessárias 14 famílias para perfazerem $80,18 \%$ do número total de árvores amostradas. Leguminosae e Myrtaceae se destacam como as mais expressivas, contribuindo com 82 e 46 indivíduos, respectivamente, totalizando $31,22 \%$ do total. Entre as Leguminosae, a sub-família Caesalpinioideae se destaca com 49 árvores $(11,95 \%)$, sendo as espécies mais abundantes Copaifera langsdorffii com 22 e C. officinalis

Tabela 1. Espécies e respectivas famílias amostradas na Reserva Florestal do Sacavém, São LuisMA. * - espécies amostradas no levantamento quantitativo; + - espécies coletas em caminhadas aleatórias. O material testemunho está indicado pelo número de coleta do $1^{\circ}$ autor entre parênteses, e pelo número do Registro Geral do HRCB.

* Anacardiaceae

* Spondias mombimL. (117) HRCB 16503

* Tapirira guianenis Aubl. (82) HRCB 16426

* Annonaceae

* Annona montana Macf. (245) HRCB 16424

* Annona sp (196) HRCB 16645

* Duguetia echinophora R.E.Fries HRCB 16474

* Ephedranthus sp 1 (F55)

* Ephedranthus sp 2 (2) HRCB 16481

* Oxandra reticulata Maas (302) HRCB 16486

* Oxandra aff. sessiliflora R.E.Fries (305) HRCB 16423

* Indeterminada 1 (9)

* Indeterminada 2 (47)

* Apocrnaceae

* Aspidosperma auriculatum Mgf. (413) HRCB 16612

+ Aspidosperma centrale Mgf. (F206) HRCB 16876

* Himatanthus articulatus (Vahl.) Woodson (104) HRCB 16564
* Araliaceae

* Didymopanax sp (4)

* Arecaceae

* Maximiliana maripa(Correa) Drude (118)

* Orbignya phalerata Mart. (215)

* Syagrus sp. (375)

* Astrocaryum vulgare Mart. (142)

* Bignoniaceae

+ Tabebuia serratifolia(Vahl.) Nich. (F191) HRCB 16870

* Tabebuia sp (185)

+ Bombacaceae

+ Pachira aquatica (Aubl.) Schum. (F153) HRCB 16929

+ Boraginaceae

+ Cordia scabrifolia DC. (F188) HRCB 16868

* Burseraceae

* Protium heptaphyllum (Aubl.) March. (F16) HRCB 16625

* Trattinickia rhoifolia Willd. (F146) HRCB 16877

* Caricaceae

* Jacaratia spinosa (Aubl.) DC. (189) . 
+ Caryocaraceae

+ Caryocar brasiliensis Camb. (F163) HRCB 16881

* Cecropiaceae

* Cecropia palmata Willd. (F170) HRCB 16911

* Celastraceae

* Indeterminada (99)

* Chrysobalanaceae

* Couepia aff. guianensis Aubl. subsp. guianensis (281) HRCB 16604

* Hirtella racemosaLam. (87) HRCB 16566

* Licania cf. incana Aubl. (298)

* Licania kunthiana Hook. f. (3) HRCB 16521

* Indeterminada (412)

+ CLUSIACEAE

+ Symphonia globuliferaL.f. (F144) HRCB 16916

+ Vismia guianensis (Aubl.) Choisy (F102) HRCB 16661

+ Cochlospermaceae

+ Cochlospermum regium (Mart. \& Schrank) Pilger (F145) HRCB 16914

* Combretaceae

* Terminalia glabrescens Mart. (250) HRCB 16613

+ ERYTHROXYLACEAE

+ Enythroxylum deciduumSt.Hil. (F204) HACB 16907

+ Erythroxylum leptoneurum Schulz. (F48) HRCB 16615

+ Enthroxylum of. ambigumm Peyr. (F215) HRCB 16908

* Euphorbiaceae

- Actinostemon concepciones (Chadat \& Hassl.) Pox \& Hoffm. (404) HRCB 16611

+ Croton cajuçaraBenth (F220) HRCB 16919

+ Hieronyma laxiflora (Tul.) M.Arg. (F154) HRCB 16920

+ Manihot coenulescens(Pohl.) M. Arg. (F228) HRCB 16925

* Pogonophora schomburgkiana Miers (35) HRCB 16471
+ Richeria grandis Vahl. (F195) HRCB 16921

+ Sapium lanceolatum (M.Arg.) Hub. (F101) HRCB 16742

* Flacourtiaceae

* Banara guianensis Aubl. (F64) HRCB 16633

+ Casearia arborea (Rich.) Urban (F51) HRCB 16634

* Casearia javitensis H.B.K. (F34) HRCB 16626

* Casearia cf. negrensis Eichl.(114) HRCB 16602

* Casearia sp. (315) HRCB 16740

* Indeterminada (154)

* Hippocrateaceae

* Cheiloclinium cognatum Miers (F24) HRCB 16763

* Lauraceae

* Ocotea cujumary Mart. (37) HRCB 16421

* Indeterminada (83)

* Lecythidaceae

+ Gustavia augustaL. (F119) HRCB 16931

+ Lecythis /urida (Miers) Mori (F187) HRCB 16926

* Indeterminada (64)

* Leguminosae-Caesalpinioideae

* Copaifera langsdorfiiDesf. (F149) HRCB 16905

* Copaifera officinalis Willd. (112) HRCB 16567

* Hymenaea courbaril L. (285) HRCB 16732

* Hymenaea panifoliaHuber (F185) HRCB 16912

+ Senna georgica Irwin \& Barneby (F113) HRCB 16923

* Senna sylvestris (Vell.) Irwin \& Barneby (198) HRCB 16509

+ Swartzia flaemingii Radl. (F197) HRCB 16924

* Indeterminada (58)

* Leguminosae-Mimosoideae 
* Abarema cochleata (Willd.) Barneby \& Grimes (94) HRCB 16475

+ Abarema jupumba (Willd.) Briton \& Killip. var. jupumba (F8) HRCB 16738

* Enterolobium schomburgkii Benth. (36) HRCB 16570

* Inga alba (S.W.) Willd. (F152) HRCB 16922

* Inga falcistipula Ducke (F123) HRCB 16932

+ Inga nitida Willd. (F151) HRCB 16893

*Inga thibaudianaD.C. (F178) HRCB 16889

+ Pithecellobium foliolosum Benth. (F142) HRCB 16913

+ Pithecelobium saman var. acutifolium Benth. (F200) HRCB 16874

* Indeterminada (233)

* Leguminosae-Papilionoideae

+ Andira retusa (Lam.) H.B.K. (F62) HRCB 16748

* Dipterix lacunifera Ducke (343) HRCB 16496

*Pterocarpus rorhii Vahl. (282) HRCB 16593

* Lythraceae

* Lafoensia sp. (372)

* Malpighiaceae

* Byrsonima laxiflora Griseb. (248) HRCB 16502

* Melastomataceae

+ Miconia albicans (S.W.) Triana (F29) HRCB 16637

* Miconiacf. serialisDC. (262) HRCB 16465

* Mouriri cearensis Huber (259) HRCB 16647

* Meliaceae

* Carapa guianensis Aubl. (F127) HRCB 16934

* Guarea guidonia(L.) Sleumer (200) HACB 16467

* Indeterminada (120)

* Monimiaceae

* Siparuna guianensis Aubl. (F71) HRCB 16772
* Moraceae

* Artocarpus integrifolia L. (170)

* Ficus citrifolia P.Miller (134) HRCB 16513

* Ficus nymphaeaefolia P.Miller (138)

* Ficus sp (110)

+ Mrrsinaceae

+ Cybianthus spicatusH.B.K. (F218) HRCB 16930

* Myristicaceae

* Virola callophylla Warb. (140) HRCB 16510

* Myrtaceae

* Campomanesia aromatica (Aubl.) Griseb. (256) HRCB 16493

* Eugenia cachoerensis Berg. (16) HRCB 16643

* Eugenia egrensis DC. (421) HRCB 16765

* Eugenia florida DC. (F36) HRCB 16628

* Eugenia lambertiana DC. var. lambertiana (F84) HRCB 16752

* Eugenia punicifolia (H.B.K.) DC. (F87) HRCB 16753

* Eugenia sp (F221) HRCB 16915

* Myrcia amazonicaDC. (266) HRCB 16490

* Myrcia cuprea (Berg.) Klaers. (F141) HRCB 16918

* Myrcia neesiana DC. (26) HRCB 16488

+ Myrcia rostrata DC. (F10) HRCB 16630

* Myrcia sp (91)

+ Myrciaria cf. dubia (H.B.K.) Mc Vaugh (F95) HRCB 16757

* Myrciaria tenella (DC.) Berg (374) HRCB 16478

* Indeterminada (411)

* Nrctaginaceae

* Guapira opposita (Vell.) Reitz (F214) HRCB 16928

* Bougainvillea sp. (73)

+ Ochnaceae

+ Ouratea castanaefolia (DC.) Engl. (F198) HRCB 16897

+ OlacaCeaE

+ Heisteria sp. (F122) HRCB 16898 
+ Schoepfia brasiliensis DC. (F114) HRCB 16927

* Polygonaceae

* Coccoloba pichuna Huber (135) HRCB 16418

* Coccoloba sp (422)

+ Rhizophoraceae

+ Cassipourea guinensis Aubl. (F190)

* RUBIACEAE

* Alibertia edulis (L.Rich.) A.Rich. ex D.C. (F67) HRCB 16664

+ Alibertia myrciifolia (Spruce) Schum (F169) HRCB 16909.

+ Chiococca brachiata R. et P. (F30) HRCB16649

* Chomelia barbellata Standl. HRCB 16507

* Isertia bullata Schum. (51) HRCB 16427

* Ixora aff. davisii Sandw. (414)

* Posoqueria latifolia (Rudge) Roem. \& Schult. (F86) HRCB 16776

+ Rudgea jasminoides (Cham.) M. Arg. (F75)

*Indeterminada (408)

+ Rutaceae

+ Zanthoxylum rhoifolium Lam. (F81) HRCB 16662

* Sapindaceae

* Allophylus edulis St.Hil. (F225) HRCB 16891

* Matayba guianensis Aubl. (207) HRCB 16487

"Pseudima frutescens(Aubl.) Radlk. (353) HRCB 16498

* Talisia sp. (122) HRCB 16520

com 13 indivíduos; as sub-famílias Mimosoideae e Papilionoideae contribuem com $17(4,15 \%)$ e 16 $(3,90 \%)$ indivíduos, respectivamente, sendo a abundância devida, principalmente, a Inga alba com 8 e Dipteryx lacunifera com 14
* Indeterminada 1 (172)

* Indeterminada 2 (147)

* Sapotaceae

+ Pouteria macrophylla (Lam.) Eyma (F177) HRCB 16910

* Pouteria reticulata (Engl.) Eyma subsp. reticulata (96) HRCB 16470

+ Pouteria sp. (F41) HRC8 16624

* Indeterminada (60)

* Simaroubaceae

* Simaba guianensis Aubl. subsp. ecaudata Cronq. (F38) HRCB 16620

* Indeterminada 1 (269)

* Indeterminada 2 (191)

+ Solanaceae

+ Solanum caavurana Vell. (F23) HRCB 16627

+ Solanum paludosum Moric. (F176) HRCB 16895

+ Sterculiaceae

+ Sterculia striata St. Hill. et Naud. (F104) HRCB 16653

+ Tillaceae

+ Luhea cymulosa Spruce (F148) HRCB 16906

+ Luhea speciosa Willd. (F199) HRCB 16917

* Ulmaceae

* Trema micrantha Blume (160) HRCB 16514

+ Verbenaceae

+ Vitex schomburgkianaDC. (F184) HRCB 16933

* VochysIaCEAE

* Qualea parvifloraMart. (42) HRCB 16417

espécimes. Entre as Myrtaceae, Myrcia amazonica com 9, M. cuprea com 6, M. neesiana, Campomanesia aromatica e uma espécie não identificada (Myrtaceae Indet.), todas com 5 indivíduos, são as espécies mais abundantes. 
Em seguida aparecem as Chrysobalanaceae, com 37 árvores, tendo em Licania cf. incana com $23 \mathrm{e}$ L. Kunthiana com 9 indivíduos, sua principal contribuição, e Meliaceae com 32 indivíduos, sendo representada principalmente por Guarea gaidonia, com 24 árvores.

Annonaceate e Arecaceae contribuíram com 19 e 17 indivíduos, tendo em Annona montana com $7 \mathrm{e}$ Maximiliana maripa com 12 árvores, as espécies mais abundantes. Burseraceae, e uma espécie cuja família é desconhecida (Desconhecida 1) contribuiram com 16 e 15 indivíduos, sendo que Protium heptaphyllum com 15 árvores é praticamente a responsável pela abundância das Burseraceae. Melastomataceate e Cecropiaceae contribuíram com 13 individuos cada uma, Miconia ef. serialis com 8 e Cecropia palmata com 13 árvores amostradas, representando as espécies mais abundantes.

Em seguida aparecem as Polygonaceae, Apocynaceae, Sapindaceae e Euphorbiaceae. respectivamente com 11,10,9 e 9 individuos. Entre as Polygonaceae. Coccoloba pichuna com 10 é a mais abundante; Himatanthus articulatus e Aspidosperma auriculatum, ambas com 5, respondem pela abundância das Apocynaceae; nas Sapindaceae a abundância está mais ou menos distribuída entre suas seis espécies. enquanto que Artinostemon concepciones com 6 é a mais abundante entre as Euphorbiaceae. Os demais 81 indivíduos amostrados, que

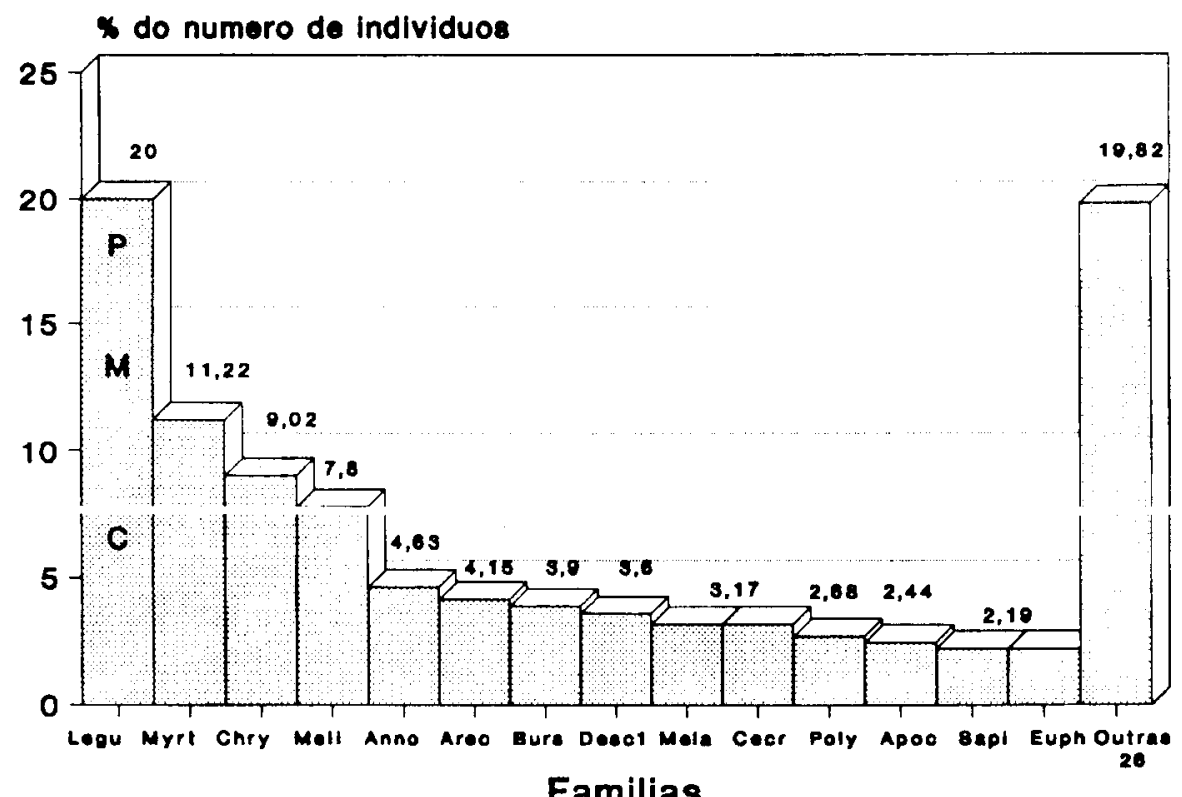

Figura 4. Distribuição do número de árvores por família, perfazendo $80,18 \%$ do total amostrado na Reserva Florestal do Sacavém. São Luís - MA. 
perfazem $19,82 \%$ do total, estão distribuídos em outras 26 famílias.

De acordo com a Figura 5, verificase que 11 famílias contribuíram com $65,47 \%$ do total de espécies. As familias que apresentaram maior riqueza foram Leguminosae e Myrtaceae, com 14 e 1.3 espécies, respectivamente, perfazendo $24,55 \%$ do total. Entre as Leguminosae, as sub-famílias Caesalpinioideae e Mimosoideae tiveram 6 espécies cada uma e a sub-família Papilionoideae apresentou apenas 2 .

A seguir aparecem as Annonaceae com 9 espécies, Sapindaceae e Rubiaceae com 6, Chrysobalanaceae e Flacourtiaceae com 5, Arecaceae e Moraceae com 4 e Meliaceae e Simarubaceae com 3. Burseraceae, Apocynaceae, Anacardiaceae, Melastomataceae, Polygonaceae,
Lauraceae, Euphorbiaceae, Nyctaginaceae e Sapotaceae com 2 espécies. Outras 20 familias, cada qual com uma única espécie, somam os $34,53 \%$ restantes.

\section{Estrutura da Vegetação}

\section{Classes de Diâmetro}

A Figura 6 apresenta a distribuição da frequiência dos diâmetros de todos os indivíduos amostrados $(n=410)$ em classes de $10 \mathrm{~cm}$. Verifica-se que mais da metade dos indivíduos (224, equivalente a $54,63 \%$ ) apresenta diâmetro superior a $10 \mathrm{~cm}$, esse valor subindo para $89,75 \%$ (368 árvores) quando se considera as classes até $30 \mathrm{~cm}$. Nota-se também que não há interrupções de classes e que a distribuição apresenta uma tendência à forma de " $\mathrm{J}$ " invertido.

A razão $(q)$ entre a frequiência de

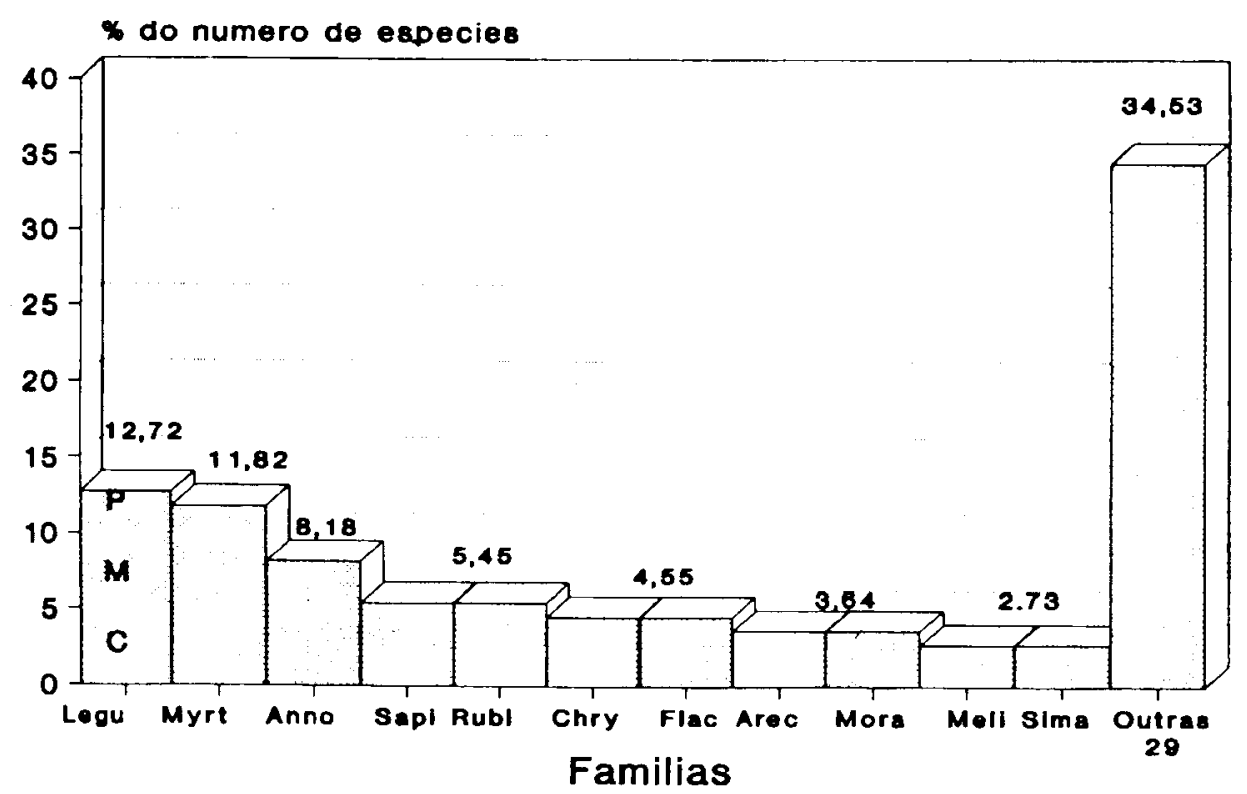

Figura 5. Distribuição do número de espécies por família, perfazendo $65,47 \%$ do número total amostrado na Reserva Florestal do Sacavém, São Luís - MA. 


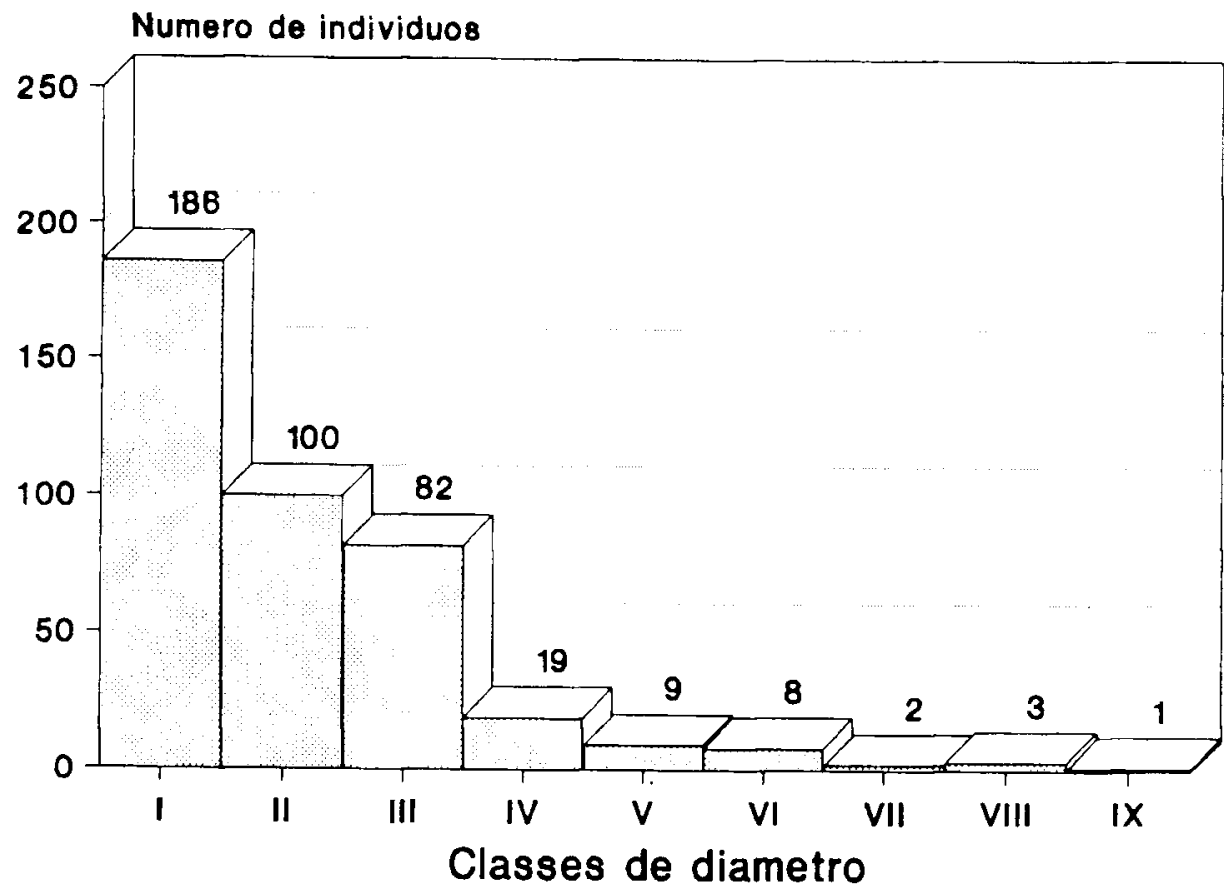

Figura 6. Distribuição de frequência de diâmetro das árvores $(\mathrm{N}=410)$, na Reserva Florestal do Sacavém, São Luís - MA. Classes de diâmetro de acordo com a Tabela 2.

Tabela 2. Distribuição do número de árvores em classes de DAP, Reserva Florestal do Sacalvém, São Luís - MA.

\begin{tabular}{|c|c|c|c|c|}
\hline № da Classe & $\begin{array}{l}\text { Intervalo de } \\
\text { Classe }(\mathrm{cm})\end{array}$ & $\begin{array}{c}\quad N^{\circ} \text { de } \\
\text { Individuos }\end{array}$ & $\%$ & Razão "Q" \\
\hline 1 & $0,1 \cdots 10,0$ & 186 & 45,36 & 0,53 \\
\hline II & $10,1 \ldots 20,0$ & 100 & 24,39 & 0,82 \\
\hline III & $20,1 \cdots 30,0$ & 82 & 20,00 & 0,23 \\
\hline IV & $30,1-.-40,0$ & 19 & 4,63 & 0.47 \\
\hline V & $40,1 \ldots 50,0$ & 9 & 2,19 & 0,88 \\
\hline VI & $50,1 \cdots 60,0$ & 8 & 1,95 & 0,25 \\
\hline VII & $60,1 \ldots 70,0$ & 2 & 0,49 & 1,50 \\
\hline VIII & $70,1--80,0$ & 3 & 0,73 & 0,33 \\
\hline IX & $80,1 \ldots 90,0$ & 1 & 0,24 & $\cdots$ \\
\hline TOTAL & $\cdots$ & 410 & 99,98 & $\cdots$ \\
\hline
\end{tabular}


uma classe diamétrica para a classe imediatamente inferior varia grandemente, como pode ser observado na Tabela 2 , indicando ou uma mortalidade muito alta (entre as classes II e III), ou um recrutamento muito grande (entre as classes VI e VII).

Para as espécies que apresentaram 10 ou mais indivíduos, a distribuição de freqüência das classes de diâmetro está representada na Figura 7. Guarea guidonia (Fig. 7A), a mais abundante de toda a fitocenose, apresenta seus indivíduos distribuídos em 4 classes contínuas de DAP, com $70,83 \%$ dos indivíduos concentrados nas classes acima de 10 $\mathrm{cm}$. A razão "q" é de 1,71 entre a primeira e a segunda classes, 0,33 entre a segunda e a terceira e de 0,25 entre esta e a última classe.

Os indivíduos de Licania cf. incana (Fig. 7B), encontram-se distribuídos em 6 classes, apresentando interrupção na classe $V$. Quase a totalidade das árvores $(95,65 \%)$ se concentram nas classes acima de $10 \mathrm{~cm}$ de DAP. O quociente "q" é de 5 entre a primeira e a segunda classes, 2,5 entre a segunda e a terceira, 0,23 entre esta e a quarta classe.

Copaifera langsdorffii (Fig. 7C), distribuída em apenas 2 classes de DAP, apresenta indivíduos apenas a partir da segunda, estando $77,27 \%$ deles na terceira classe. $O$ quociente "q" entre uma classe e outra é de 3,4.

Os indivíduos de Protium heptaphyllum (Fig. 7D), distribuídos em 3 classes de DAP, se concentram a maioria $(53,33 \%)$ na primeira classe. A razão "q" é de 0,62 entre as duas primeiras classes e de 0,4 entre a segunda e a terceira. Observa-se que esta espécie apresenta, assim como a distribuição geral dos diâmetros, uma tendência à forma de "J" invertido.

A distribuição dos indivíduos de Dipteryx lacunifera (Fig. 7E) em 5 classes contínuas de DAP é variável entre as classes, estando a maioria $(78,55 \%)$ nas classes superiores a 10 $\mathrm{cm}$. A razão "q" é de 0,66 entre a primeira e a segunda classes, 2 entre a segunda e a terceira, 0,75 entre a terceira e a quarta e 0,66 entre esta e a última classe.

Copaifera officinalis (Fig. 7F), também com apenas 2 classes de DAP, apresenta indivíduos somente a partir da segunda classe, com a maioria deles $(61,54 \%)$ na terceira classe. O quociente "q" entre as classes é de 1,6.

Cecropia palmata (Fig. 7G), com apenas 2 classes de DAP, apresenta quase a totalidade dos indivíduos $(92,31 \%)$ na primeira classe, sendo a razão " $q$ " entre as classes igual a 0,07 .

Maximiliana maripa (Fig. 7H), com 3 classes de DAP, apresenta indivíduos somente a partir da terceira classe, encontrando-se nesta a maior concentração $(75,00 \%)$. A razão "q" é de 0,22 entre a primeira e a segunda classes, e de 0,5 entre esta e a última.

Os indivíduos de Coccoloba pichuna (Fig. 7I), distribuídos em 2 classes, apresentam $60,00 \%$ do total na primeira classe de DAP, sendo a razão entre as classes de 0,66. 


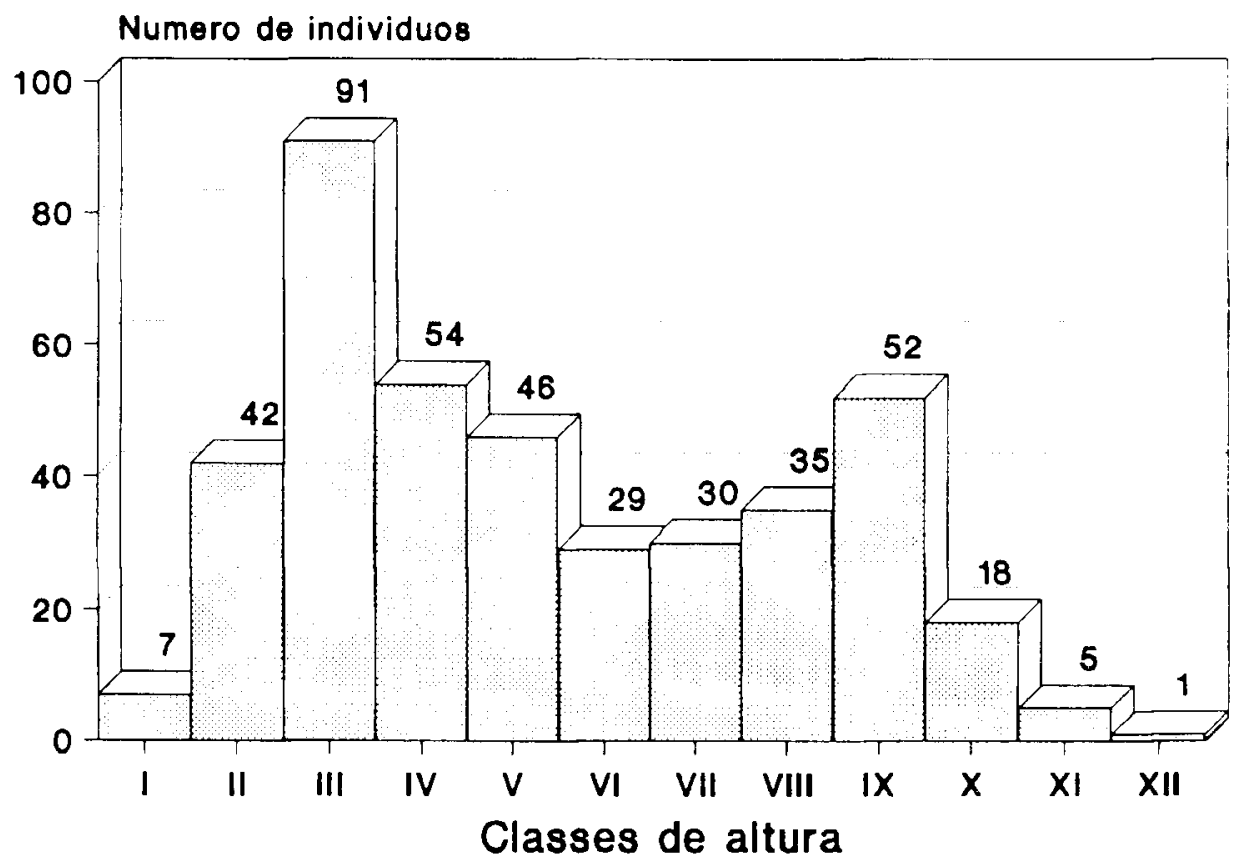

Figura 7. Distribuição de frequência de DAP das espécies com 10 ou mais indivíduos, Reserva Florestal do Sacavém, São Luís - MA. Classes de diâmetro de acordo com a Tabela 2. A Guarea gaidonia; B - Licania cf, incana; C - Copaifera langsdorffii; D - Protium heptaphlllam; E - Dipteryx lacanifera; F - Copaifera officinalis; G - Cecropia palmata; H - Maximiliana maripa; I - Coccolola pichuna.

\section{Classes de Altura}

A Figura 8 representa, em histograma, as classes de altura das copas, com intervalo de variação de $2,0 \mathrm{~m}$ e o número de indivíduos de cada classe. Pela análise da figura pode-se constatar que até $12 \mathrm{~m}$ de altura (classes de I a V) existem 240 indivíduos, que perfazem $58,53 \%$ do número total. Acima desta altura existem 170 indivíduos, perfazendo $41,46 \%$ do total amostrado. A altura média das árvores foi de $11,16 \mathrm{~m}$, com um mínimo de $2,0 \mathrm{~m}$ e um máximo de $25,0 \mathrm{~m}$.

Considerando a composição florística, nas classes até 12,0 m de altura existem 81 espécies $(77,88 \%)$, das quais $58(55,76 \%$ do total de espécies) são exclusivas, e 5 morfoespécies (4 exclusivas). Acima de !2,0 $\mathrm{m}$ de altura existem 47 espécies $(45,19 \%)$, das quais $23(22,11 \%)$ são exclusivas, havendo, portanto, 23 espécies $(22,11 \%)$ que ocorrem nessas duas classes de altura. Nas classes de altura acima de $12,0 \mathrm{~m}$, existem ainda 2 morfo-espécies (1 exclusiva). totalizando as 110 espécies e morfoespécies consideradas.

O índice de diversidade de Shannon e Weaver ( $\left.\mathrm{H}^{\prime}\right)$ calculado para esta fitocenose foi de 4,186 (Tab.3). 


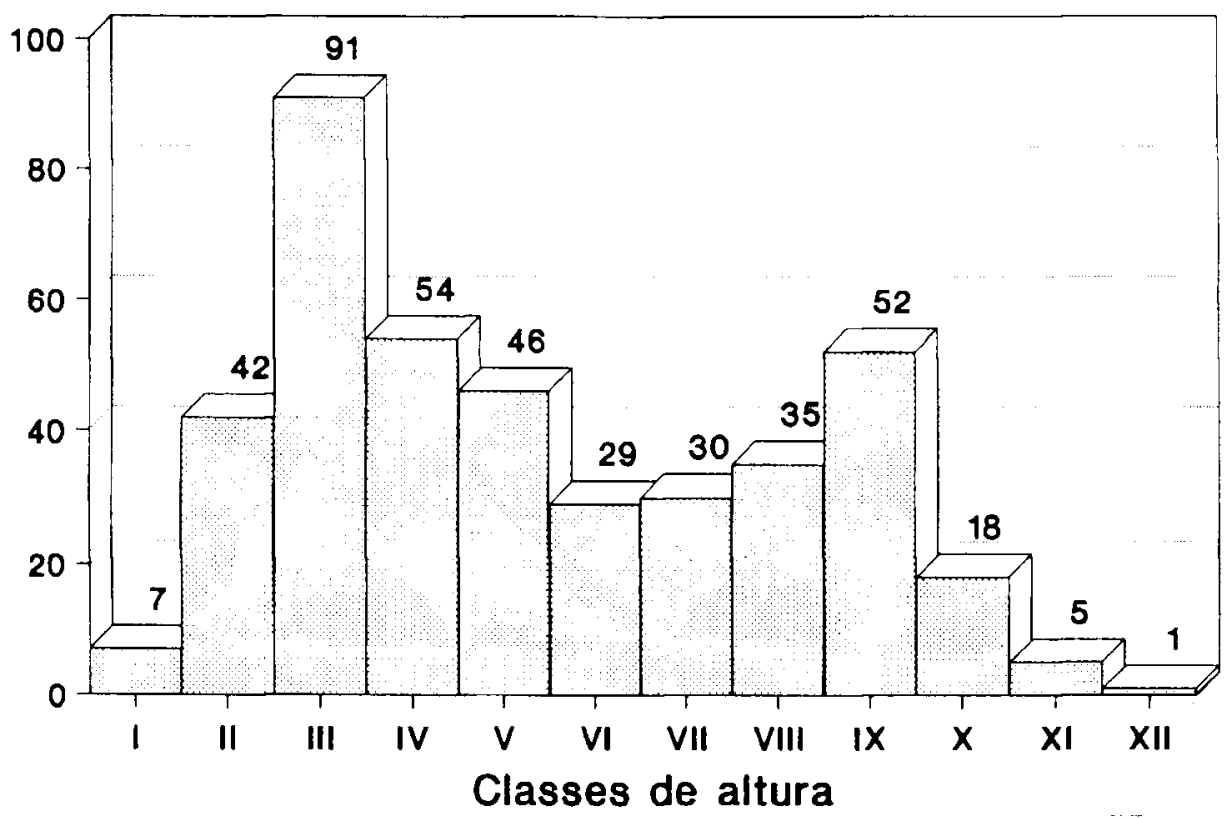

Figura 8. Distribuição de lrequência das classes de altura das árvores $(N=410)$ da mata da Reserva Florestal do Saciavém. São Luís-MA. Classes de altura: 1) 2 - 4m; II) 4 - 6m; III) 6 - $8 \mathrm{~m} ; \mathrm{IV}) 8$ - I0m: V) 10-12m: VI) 12 - 14m: VII) $14-16 \mathrm{~m}$; VIII) $16-18 \mathrm{~m} ; \mathrm{IX}) 18-20 \mathrm{~m}$; X) $20-22 \mathrm{~m} ; \mathrm{XI}) 22-24 \mathrm{~m}: \mathrm{XII)} 24-26 \mathrm{~m}$.

\section{DISCUSSÃO Composição florística}

A riqueza da flora arbórea é a característica mais importante da floresta tropical úmida e, dela, muitas de suas outras características são diretamente dependentes. As árvores de espécies diferentes são mais comumente encontradas misturadas em proporções razoavelmente iguais; mais raramente, uma ou duas espécies são muito mais abundantes que as outras (RICHARDS, 1952).

Quando se compara os resultados dos vários levantamentos florísticos realizados na Amazônia, como pode ser observado na Tabela 3 , notam-se expressivas variações no número de táxons por unidade de área, em regiões distintas, mesmo com metodologia semelhante. Esta diferença é bem visível entre os resultados de MACIEL \& LISBOA (1989), que registraram 85 espécies/ha e BALÉE (1987), com 154 espécies/ha. O primeiro estudo foi realizado em Rondônia, enquanto que o último foi feito no Pará, regiões muito distantes entre si e que, portanto, estão sujeitas a fatores ambientais distintos. De fato, a composição florística e a diversidade mudam drasticamente de um local para outro (MORI et al., 1989) e essa variação é tanto maior quanto mais se distanciam as áreals entre si. Também é importante o sentido desse distanciamento - se de norte a sul ou, 
de leste a oeste - porque em cadal caso, diferentes tipos de barreiras ecológicas funcionaram na sua evolução (PIRES, 1980). Além disso, DUCKE \& BLACK (1954) já haviam alertado para o fato de que, na Amizônia, a longitude desempenha um papel muito mais importante que a latitude na composição da flora, observando que todas as informações acusam maior número de espécies para o centro e noroeste da região, que para as partes orientais e ocidentais.

No levantamento realizado neste

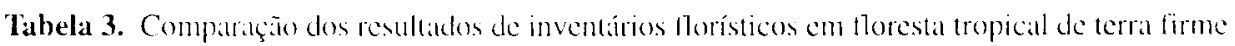
na Amazonia Brasileira.

\begin{tabular}{|c|c|c|c|c|c|c|c|c|c|}
\hline Autor(es) & Localidade & $\begin{array}{c}\text { Área } \\
\text { amostrada }\end{array}$ & $\begin{array}{l}\text { DAP } \\
\text { Min } \\
(\mathrm{cm})\end{array}$ & $\begin{array}{c}N \\
\text { Ind. }\end{array}$ & $\begin{array}{c}\mathrm{N} \\
\text { Fam }\end{array}$ & $\begin{array}{c}N \\
\text { Gên. }\end{array}$ & $\begin{array}{c}N \\
\text { Spp }\end{array}$ & $\begin{array}{c}A B \\
(\mathrm{~m} 2)\end{array}$ & $H^{*}$ \\
\hline $\begin{array}{l}\text { BALEE,W. } \\
\text { (1986) }\end{array}$ & $\begin{array}{l}\text { Bacia do rio } \\
\text { Turiacu-MA }\end{array}$ & 1 ha $500 \times 20 m$ & 10 & 519 & 38 & - & 123 & - & $\cdot$ \\
\hline $\begin{array}{l}\text { BALLE,W. } \\
\text { (1987) }\end{array}$ & $\begin{array}{l}\text { Bacia do rio } \\
\text { Gurupi-PA }\end{array}$ & 1 ha $1000 \times 10$ & 10 & 474 & - & - & 154 & - & - \\
\hline $\begin{array}{l}\text { BLACK et al. } \\
\text { (1950) }\end{array}$ & Belém - PA & 1 ha $100 \times 100 m$ & 10 & 423 & 31 & 65 & 87 & - & $3,72^{*}$ \\
\hline $\begin{array}{l}\text { CAIN et al. } \\
\text { (1956) }\end{array}$ & $\begin{array}{l}\text { Mocambo, Belém- } \\
\text { PA }\end{array}$ & $\begin{array}{c}2 \mathrm{ha} \\
20 \text { de } 100 \times 10 \mathrm{~m}\end{array}$ & 10 & $\begin{array}{c}897 \\
449 \text { ha }\end{array}$ & 39 & 100 & 153 & $\begin{array}{c}65,20 \\
32,6 / \text { ha }\end{array}$ & $4,07^{\circ}$ \\
\hline $\begin{array}{l}\text { CAMPBE } 1 \\
\text { et al.(1986 }\end{array}$ & Rio Xingu - PA & 3 ha $3000 \times 10 \mathrm{~m}$ & 10 & $\begin{array}{c}1984 \\
634 / \mathrm{ha}\end{array}$ & 39 & 127 & 265 & $\begin{array}{c}123,63 \\
41,21 \text { ha }\end{array}$ & $4,51^{*}$ \\
\hline $\begin{array}{l}\text { CARVALHO } \\
\text { et al. }(1986)\end{array}$ & $\begin{array}{l}\text { Planalto de } \\
\text { Belterra-PA }\end{array}$ & $\begin{array}{c}5 \mathrm{ha} \\
5 \text { de } 100 \times 100 \mathrm{~m}\end{array}$ & 2,5 & 2881 & 40 & 84 & 103 & $20,05 \mathrm{ha}$ & - \\
\hline \multirow[t]{2}{*}{$\begin{array}{l}\text { DANTAS \& } \\
\text { MUER } \\
(1979)\end{array}$} & $\begin{array}{l}\text { Rod. } \\
\text { Transamazônica, } \\
\text { km23 - PA }\end{array}$ & $\begin{array}{c}1 \text { ha } \\
40 \text { de } 25 \times 10 \mathrm{~m}\end{array}$ & 9,55 & 577 & 29 & 79 & 101 & - & - \\
\hline & $\begin{array}{l}\text { Rod. } \\
\text { Transamazônica, } \\
\text { km } 101 \text { - PA }\end{array}$ & $\begin{array}{c}0,5 \text { ha } \\
20 \text { de } 25 \times 10 \mathrm{~m}\end{array}$ & 9,55 & $\begin{array}{l}300 \\
600 \mathrm{Ma}\end{array}$ & 30 & 65 & 89 & - & - \\
\hline $\begin{array}{l}\text { DANTAS et al. } \\
(1980)\end{array}$ & Capitão Poco - PA & $\begin{array}{c}1 \text { ha } \\
40 \text { de } 25 \times 10 \mathrm{~m}\end{array}$ & 9,55 & 504 & 39 & 86 & 121 & $\cdot$ & - \\
\hline $\begin{array}{l}\text { USBOA } \\
\text { (1989) }\end{array}$ & Rondônia & $\begin{array}{c}0,5 \mathrm{ha} \\
20 \text { de } 25 \times 10 \mathrm{~m}\end{array}$ & 4.8 & $\begin{array}{c}760 \\
1520 \text { ha }\end{array}$ & 39 & - & 113 & $\begin{array}{c}11,74 \\
23,48 \mathrm{ha}\end{array}$ & \\
\hline $\begin{array}{l}\text { USBOA \& } \\
\text { USBOA } \\
(1994)\end{array}$ & $\begin{array}{l}\text { Rod.RO-429, km } \\
\text { 90-RO }\end{array}$ & $\begin{array}{c}1 \text { ha } \\
40 \text { de } 25 \times 10 \mathrm{~m}\end{array}$ & 9,55 & 593 & - & - & 128 & 26.07 & 4,26 \\
\hline $\begin{array}{l}\text { MACIEL\& } \\
\text { USBOA } \\
(1989)\end{array}$ & $\begin{array}{l}\text { Rod.RO-429, km } \\
16-R O\end{array}$ & $\begin{array}{c}1 \text { ha } \\
40 \text { de } 25 \times 10 \mathrm{~m}\end{array}$ & 9,55 & 602 & 32 & - & 85 & 34,54 & - \\
\hline $\begin{array}{l}\text { MORELATO } \\
\text { \& ROSA, } \\
(1991)\end{array}$ & $\begin{array}{l}\text { Núcleo de } \\
\text { Afloramento de } \\
\text { Minério, Serra } \\
\text { Norte, Carajás - PA }\end{array}$ & $\begin{array}{c}0,29 \mathrm{ha} \\
29 \text { de } 10 \times 10 \mathrm{~m}\end{array}$ & 5 & 437 & 40 & 80 & 100 & - & 3,98 \\
\hline $\begin{array}{l}\text { MORI et al., } \\
\text { (1959) }\end{array}$ & Carnaipi - AP & $\begin{array}{c}1 \text { ha } \\
40 \text { de } 25 \times 10 \mathrm{~m}\end{array}$ & 10 & 484 & 39 & 83 & 122 & 21,59 & - \\
\hline $\begin{array}{l}\text { PIRES et al., } \\
\text { (1953) }\end{array}$ & Castanhal - PA & $\begin{array}{l}\text { 3,5 ha } \\
\text { diagrama } \\
\text { irregular }\end{array}$ & 10 & $\begin{array}{c}1482 \\
423 \mathrm{ha}\end{array}$ & 47 & 139 & 179 & - & $4,30^{*}$ \\
\hline
\end{tabular}


continuação tabela 3.

\begin{tabular}{|c|c|c|c|c|c|c|c|c|c|}
\hline $\begin{array}{l}\text { PRANCE et al. } \\
\text { (1976) }\end{array}$ & Manaus - AM & $\begin{array}{c}1 \mathrm{ha} \\
12 \mathrm{de} 80 \times 10 \mathrm{~m}\end{array}$ & 15 & 350 & 41 & 125 & 179 & - & $4,76^{*}$ \\
\hline \multirow[t]{2}{*}{$\begin{array}{l}\text { RODRIGUES, } \\
\text { (1963) }\end{array}$} & Serra do Navio - AP & $\begin{array}{c}1,5 \mathrm{ha} \\
15 \text { de } 100 \times 10 \mathrm{~m}\end{array}$ & 15 & $\begin{array}{c}461 \\
307 \mathrm{ha}\end{array}$ & 37 & 70 & 96 & - & $3,89^{*}$ \\
\hline & Serra do Navio - AP & $\begin{array}{c}1,1 \mathrm{ha} \\
11 \mathrm{de} 100 \times 10 \mathrm{~m}\end{array}$ & 15 & $\begin{array}{c}347 \\
313 \mathrm{ha}\end{array}$ & 36 & 64 & 84 & - & - \\
\hline $\begin{array}{l}\text { SALOMÃO \& } \\
\text { USBOA } \\
(1988)\end{array}$ & Rod. BR-364 - RO & $\begin{array}{c}1 \mathrm{ha} \\
20 \mathrm{de} 25 \times 10 \mathrm{~m}\end{array}$ & 9,55 & 573 & 43 & 130 & 171 & 31,05 & 4,44 \\
\hline $\begin{array}{l}\text { SALOMĀO } \\
\text { et al. (1988) }\end{array}$ & $\begin{array}{l}\text { Minas de Ferro, } \\
\text { Serra Norte, Carajás } \\
\text { - PA }\end{array}$ & $\begin{array}{c}1 \text { ha } \\
40 \text { de } 25 \times 10 \mathrm{~m}\end{array}$ & 10 & 484 & 41 & 83 & 122 & 21,59 & 4,23 \\
\hline $\begin{array}{l}\text { SILVA et al. } \\
\text { (1986) }\end{array}$ & $\begin{array}{l}\text { Mata do Aeroporto, } \\
\text { Serra Norte, } \\
\text { Carajás-PA }\end{array}$ & $\begin{array}{c}1 \text { ha } \\
20 \text { de } 25 \times 20 m\end{array}$ & 9,55 & 536 & 41 & 96 & 130 & 28,59 & 4,08 \\
\hline $\begin{array}{l}\text { SILVA et al. } \\
\text { (1987) }\end{array}$ & $\begin{array}{l}\text { Bacia do rio Gelado, } \\
\text { Serra Norte, Carajás } \\
\text { - PA }\end{array}$ & $\begin{array}{c}1 \text { ha } \\
40 \text { de } 25 \times 10 m\end{array}$ & 9,55 & 531 & 37 & 96 & 116 & 21,08 & - \\
\hline \multirow[t]{2}{*}{$\begin{array}{l}\text { SILVA \& } \\
\text { ROSA } \\
\text { (1989) }\end{array}$} & $\begin{array}{l}\text { Mina de Cobre } \\
\text { 3-ALFA, Serra } \\
\text { Norte,Carajás-PA }\end{array}$ & $\begin{array}{c}1 \text { ha } \\
40 \text { de } 25 \times 10 \mathrm{~m}\end{array}$ & 9,55 & 469 & 39 & 90 & 121 & 21,67 & - \\
\hline & $\begin{array}{l}\text { Mina de Cobre } \\
\text { Pojuca, Serra } \\
\text { Norte,Carajás-PA }\end{array}$ & $\begin{array}{c}1 \text { ha } \\
40 \text { de } 25 \times 10 \mathrm{~m}\end{array}$ & 9,55 & 552 & 39 & 89 & 119 & 20,27 & - \\
\hline $\begin{array}{l}\text { SiLVA } \\
\text { et al., apud } \\
\text { SALOMĀO } \\
\text { et al., } 1988\end{array}$ & $\begin{array}{l}\text { Mina de Mangânes, } \\
\text { Serra Norte, } \\
\text { Carajás-PA }\end{array}$ & $\begin{array}{c}1 \mathrm{ha} \\
40 \text { de } 25 \times 10 \mathrm{~m}\end{array}$ & 9,55 & 561 & 39 & 94 & 123 & 22,62 & - \\
\hline $\begin{array}{l}\text { SILVA } \\
\text { et al. apud } \\
\text { SALOMĀO } \\
\text { et al., } 1988\end{array}$ & Marabá - PA & $\begin{array}{c}1 \mathrm{ha} \\
40 \text { de } 25 \times 10 \mathrm{~m}\end{array}$ & 9,55 & 591 & 36 & 96 & 125 & 21,1 & - \\
\hline $\begin{array}{l}\text { SILVA } \\
\text { et al., apud } \\
\text { SALOMĀO } \\
\text { et al., } 1988 \text {. }\end{array}$ & Açailândia & $\begin{array}{c}1 \mathrm{ha} \\
20 \text { de } 25 \times 20 \mathrm{~m}\end{array}$ & 9,55 & 453 & 34 & 77 & 98 & 31,82 & - \\
\hline $\begin{array}{l}\text { SILVA } \\
\text { et al., apud } \\
\text { SALOMÃO et } \\
\text { al., } 1988\end{array}$ & Buriticupu, & $\begin{array}{c}1 \text { ha } \\
40 \text { de } 25 \times 10 \mathrm{~m}\end{array}$ & 9,55 & 449 & 27 & 60 & 75 & 17,69 & - \\
\hline $\begin{array}{l}\text { ESTE } \\
\text { TRABALHO }\end{array}$ & $\begin{array}{l}\text { Reserva Florestal do } \\
\text { Sacavem, Sāo } \\
\text { Luis-MA }\end{array}$ & $\begin{array}{c}0,5 \mathrm{ha} \\
50 \text { de } 10 \times 10 \mathrm{~m}\end{array}$ & 4,8 & $\begin{array}{c}410 \\
820 \text { ha }\end{array}$ & 34 & 66 & 104 & $\begin{array}{c}14,21 \\
28,41 \text { ha }\end{array}$ & 4,2 \\
\hline
\end{tabular}

DAP min. - diâmetro à altura do peito $(1,30 \mathrm{~m})$ mínimo; Núm. de ind. - número de indivíduos: Núm. de fam. - número de famílias; Núm de gên. - número de gêneros; Núm de spp. - número de espécies; AB - áré basal; $H^{*}$ - indice de diversidade de SHANNON \& WEAVER (" - calculado por MARTINS, 1979).

estudo, o número total de 104 espécies e 6 morfo-espécies (além de 46 espécies não amostradas quantitativamente), é maior que o número que se 
poderia esperar, uma vez que a região de estudo se encontra no extremo oriental da Floresta Amazônica. A grande riqueza de espécies, por outro lado, pode ser devida ao fato desta área apresentar um caráter transicional entre as regiões norte, nordeste e central do País, apresentando elementos de todas essas áreas. O número de espécies é comparável aos encontrados por vários autores, sendo superior aos resultados de BLACK et al.(1950), DANTAS \& MULLER (1979), MACIEL \& LISBOA (1989), RODRIGUES (1963), devendo-se, no entanto, ressaltar que essas comparações devem ser feitas com cautela, uma vez que nestes estudos foram utilizados diferentes critérios na amostragem.

Há, no entanto, grande variação tanto na área quanto na escolha do diâmetro mínimo dos indivíduos a serem amostrados, aspectos que irão refletir tanto na composição florística quanto na estrutura da vegetação estudada. Assim é que BALÉE (1986, 1987), BLACK et al. (1950), MORI et al. (1989) e SALOMÃO et al. (1988) utilizaram amostras de 1 ha e DAP mínimo de $10 \mathrm{~cm}$, enquanto que CAIN et al. (1956), CAMPBELL et al. (1986) e PIRES et al. (1953) também utilizaram DAP mínimo de $10 \mathrm{~cm}$, embora a área amostral tenha sido maior. Outros autores (DANTAS \& MULLER, 1979; DANTAS et al., 1980; LISBOA \& LISBOA, 1989; MACIEL \& LISBOA, 1989; SALOMÃO \& LISBOA, 1988; SILVA et al., 1986, 1987, 1989), contudo, utilizaram um DAP mínimo de $9,55 \mathrm{~cm}$ (equivalente a um PAP mínimo de $30 \mathrm{~cm}$ ), numa área amostral de 1 ha.

PIRES et al. (1953) chamaram a atenção para o fato de que o número de espécies arbóreas encontradas em uma amostra pequena de floresta só poderá dar informaçōes fidedignas sobre a diversidade de espécies, se o território da amostra for uniforme. É evidente que diferentes fácies. das florestas de terra firme são realmente muito distintas na composição de espécies e que qualquer estimativa da diversidade total descreverá somente a situação da fácies particular em que é feita.

Ao se comparar a diversidade das principais familias encontradas na mata da Reserva Florestal do Sacavém com outros levantamentos realizados em florestas amazônicas (Tab. 4), mesmo levando-se em consideração que os resultados foram obtidos com metodologia não uniforme. notou-se para estas florestas um certo padrão de distribuição das espécies entre as famílias. Destacam-se as Annonaceae. Apocynacede, Arecacear, Bignoniaceale. Burseraceae, Euphorbiaceae, Lauraceae, Lecythidaceae, Leguminosae (senso lato). Meliaceae, Moraceae, Myrtaceae, Rubiaceae, Rutaceae, Sapindaceae e Sapotaceae. MORI et al. (1989) citaram. além destas, as Bombacaceae, Chrysobalanaceae, Myristicaceale e Vochysiaceate como as famílias arbóreas mais importantes em florestas neotropicais úmidas de baixada.

De fato, GENTRY (1986) afirmou que, embora cada local possua um conjunto de espécies quase completamente diferente, a composição a nível de família dessas florestas é marcadamente similar. Não somente Leguminosae está entre as familias mais ricas em espécies em cada local, como as outras familias que ocomem são as mesmas e, aproximadamente. na mesma sequência de riquezi. de 
espécies. Pelo menos sete das onze famílias mais ricas em espécies são as mesmas em todos os locais. Esses padrões parecem sugerir que cada família deve ter uma regra específica nas comunidades neotropicais, com um grupo diferente de espécies de cada família para diferentes substratos na Amazônia.

Em relação ao número de indivíduos por família, verificam-se diferenças mais ou menos consideráveis nas diversas florestas estudadas na Amazônia (Tab. 4). As famílias que mais se destacam são Arecaceae, Bignoniaceae, Burseraceae, Cochlospermaceae, Combretaceae, Euphorbiaceae, Lauraceae, Lecythidaceae, Leguminosae, Melastomataceae, Moraceae, Myrtaceae e Sapotaceae.

Tabela 4. Familias mais importantes de acordo com o(s) parâmetro (s) analisado (s) por diversos autores em floresta tropical de terra fïme na Amazônia Brasileira.

\begin{tabular}{|c|c|c|c|}
\hline Autor(es) & Local & Familia & $\begin{array}{c}\text { Parâmetro } \\
\text { Analisado }\end{array}$ \\
\hline BALEE, W.(1966) & Bacia do rio Turiacu-MA & $\begin{array}{l}\text { Sapotaceae }(13,8 \%) \\
\text { Leguminosae }(12,2 \%)\end{array}$ & diversidade relativa \\
\hline $\begin{array}{l}\text { CAMPBEEL et al., } \\
\text { (1986) }\end{array}$ & Bacia do rio Xingu-PA & $\begin{array}{l}\text { Leguminosae }(19,6 \%) \\
\text { Moraceae }(7,9 \%) \\
\text { Palmae }(32,6 \%) \\
\text { Leguminosae }(19,7 \%)\end{array}$ & densidade relativa \\
\hline CAIN et al., (1956) & $\begin{array}{l}\text { Reserva Mocambo, } \\
\text { Belém-PA }\end{array}$ & $\begin{array}{l}\text { Burseraceae }(5,2 \%) \\
\text { Leguminosae } \\
\text { Sapotaceae }(3,3 \%)\end{array}$ & diversidade relativa \\
\hline $\begin{array}{l}\text { CARVALHO et al., } \\
\text { (1986) }\end{array}$ & $\begin{array}{l}\text { Planalto do Tapajós - } \\
\text { Belterra-PA }\end{array}$ & $\begin{array}{l}\text { Bignoniaceae; } \\
\text { Combretaceae; } \\
\text { Melastomataceae; } \\
\text { Myrtaceae } \\
\text { Leguminosae (27 spp.); } \\
\text { Apocynaceae (6); } \\
\text { Moraceae (5); } \\
\text { Euphorbiaceae (4) }\end{array}$ & densidade relativa \\
\hline DANTAS et al., (1980) & Capitāo Poco-PA & $\begin{array}{l}\text { Sapotaceae }(14 \%) \text { e } \\
\text { Leguminosae }(10,7 \%) \\
\text { Lecythidaceae }(25,4 \%)\end{array}$ & $\begin{array}{l}\text { diversidade relativa } \\
\text { densidade relativa }\end{array}$ \\
\hline LISBOA (1989) & $\begin{array}{l}\text { BR-364 (Cuiabá -Porto } \\
\text { Velho), km 17) }\end{array}$ & $\begin{array}{l}\text { Leguminosae (34 spp.); } \\
\text { Moraceae (10): } \\
\text { Euphorbiaceae (9); } \\
\text { Palmae (5) } \\
\text { Leguminosae; } \\
\text { Euphorbiaceae } \\
\text { Cochlospermaceae }\end{array}$ & diversidade relativa \\
\hline MORI et al. (1989) & Carnaipi - AP & $\begin{array}{l}\text { Leguminosae, Sapotaceae } \\
\text { Leguminosae, Lauraceae }\end{array}$ & $\begin{array}{l}\text { diversidade relativa } \\
\text { densidade relativa }\end{array}$ \\
\hline PIRES et al. (1953) & Castanhal - PA & $\begin{array}{l}\text { Leguminosae (30 spp.); } \\
\text { Sapotaceae (25); } \\
\text { Lecythidaceae (5) } \\
\text { Lecythidaceae (273 ind); } \\
\text { Sapotaceae }(266) ; \\
\text { Leguminosae (174) }\end{array}$ & densidade relativa \\
\hline
\end{tabular}


continuaçāo Tabela 4.

\begin{tabular}{|c|c|c|c|}
\hline $\begin{array}{l}\text { SALOMĀO \& LISBOA, } \\
\text { (1988) }\end{array}$ & BR-364-RO & $\begin{array}{l}\text { Leguminosae }(15,77 \%) \\
\text { Moraceae }(14,61 \%) \\
\text { Sapotaceae } *, 18 \%) \\
\text { Moraceae }(19,2 \%) ; \\
\text { Leguminosae }(14,3 \%) \\
\text { Palmae }(14,1 \%) ; \\
\text { Burseraceae }(12,2 \%)\end{array}$ & diversidade relativa \\
\hline $\begin{array}{l}\text { SALOMĀO \& ROSA, } \\
\text { (1989) }\end{array}$ & $\begin{array}{l}\text { Jazida de Arenito, } \\
\text { Serra Norte, Carajás-PA }\end{array}$ & $\begin{array}{l}\text { Leguminosae; } \\
\text { Sapotaceae; } \\
\text { Rutaceae (65 ind.); } \\
\text { Sapotaceae (32) }\end{array}$ & $\begin{array}{l}\text { diversidade relativa } \\
\text { densidade relativa }\end{array}$ \\
\hline $\begin{array}{l}\text { SALOMÄO et al.. } \\
(1988)\end{array}$ & $\begin{array}{l}\text { Minas de Ferro, Serra } \\
\text { Norte, Carajás-PA }\end{array}$ & $\begin{array}{l}\text { Leguminosae }(13,11 \%) \\
\text { Sapotaceae }(9,84 \%) \\
\text { Leguminosae }(14,05 \%) \\
\text { Lauraceae }(7,64 \%)\end{array}$ & $\begin{array}{l}\text { diversidade relativa } \\
\text { densidade relativa }\end{array}$ \\
\hline SILVA \& ROSA, (1989) & $\begin{array}{l}\text { Minas de cobre, Serra } \\
\text { Norte, Carajás - PA } \\
\text { (ÁREA A) }\end{array}$ & $\begin{array}{l}\text { Leg.Min. }(9.32 \%) \\
\text { Sapotaceae e Myrtaceae } \\
(7,62 \%)\end{array}$ & diversidade relativa \\
\hline & & $\begin{array}{l}\text { Leg.Pap. }(17,75 \%) \text {; } \\
\text { Euphorbiaceae }(9,59 \%) \\
\text { Sapotaceae }(8,31 \%) ; \text { Leg. } \\
\text { Min }(8,11 \%)\end{array}$ & densidade relativa \\
\hline & $\begin{array}{l}\text { Minas de cobre, Serra } \\
\text { Norte, Carajás-PA } \\
\text { (ÁREA B) }\end{array}$ & $\begin{array}{l}\text { Moraceae }(12,71 \%) \text {; } \\
\text { Leg.Min. }(11,86 \%) \text { e } \\
\text { Sapotaceae }(7,62 \%)\end{array}$ & diversidade relativa \\
\hline SILVA et al., (1986) & $\begin{array}{l}\text { Mata do Aeroporto, } \\
\text { Serra Norte, } \\
\text { Carajás-PA }\end{array}$ & $\begin{array}{l}\text { Leguminosae (29 spp.); } \\
\text { Moraceae (15); } \\
\text { Rubiaceae (11); } \\
\text { Bignoniaceae (10); } \\
\text { Sapindaceae (10); } \\
\text { Lauraceae e } \\
\text { Sapotaceae(9); } \\
\text { Burseraceae, Meliaceae e } \\
\text { Rutaceae (7) }\end{array}$ & diversidade relativa \\
\hline SILVA et al., (1987) & $\begin{array}{l}\text { Rio Gelado, Serra Norte, } \\
\text { Carajás-PA }\end{array}$ & $\begin{array}{l}\text { Leguminosae (35 spp.); } \\
\text { Moraceae (13); } \\
\text { Burseraceae, } \\
\text { Sapindaceae e Palmae } \\
\text { (9); Annonaceae e } \\
\text { Lecythidaceae (7) }\end{array}$ & diversidade relativa \\
\hline ESTE TRABALHO & $\begin{array}{l}\text { Reserva Florestal do } \\
\text { Sacavem - Sāo Luis-MA }\end{array}$ & $\begin{array}{l}\text { Leguminosae }(12,7 \%) \\
\text { Myrtaceae }(11,8 \%) \\
\text { Annonaceae }(8,2 \%) \\
\text { Sapindaceae }(5,45 \%) \\
\text { Rubiaceae }(5,45 \%)\end{array}$ & diversidade relativa \\
\hline & & $\begin{array}{l}\text { Leguminosae }(20 \%) \text {; } \\
\text { Myrtaceae }(11,2 \%) \text {; } \\
\text { Chysobalanaceae }(9 \%) \text {; } \\
\text { Meliaceae }(7,8 \%) \\
\text { Annonaceae }(4,6 \%)\end{array}$ & densidade relativa \\
\hline
\end{tabular}

Leguminosae e Myrtacede predominam grandemente em número de indivíduos na área em estudo (Fig. 4), somando $31,22 \%$ do total amostrado. devido a um grupo e não apenas a uma única espécie. Leguminosae se destaca, 
também, como a família mais diversificada.

Essas observações confirmam que entre as florestas amazônicas consideradas, a maioria difere quanto à família mais importante em diversidade e abundância, mesmo quando na amostragem é usado o mesmo método e critério. AUBRÉVILLE (1938 apud RICHARDS, 1952) mostrou que, antes de tudo, os indivíduos das espécies que compõem a floresta úmida têm vários tipos diferentes de distribuição e que, devido à essas diferenças na distribuição, a floresta deve, necessariamente, diferir na composição de um lugar para outro.

RICHARDS (1952) ainda concluiu dizendo que a grande riqueza florística da floresta tropical é devida, parcialmente, às condições adequadas que favorecem uma alta taxa de especiação, principalmente o clima, que é favorável ao crescimento e reprodução das plantas em todas as estações. $\mathrm{O}$ autor ainda considerou que esta riqueza é largamente devida à grande idade da extensa massa de terra tropical, que tem tornado possível a persistência da vegetação mais ou menos como aquela dos dias de um desconhecido, mas certamente distante, período geológico. É por esta causa, provavelmente, que até em regiões largamente separadas, a floresta tropical mostra considerável uniformidade nas características gerais de sua composição.

Os valores obtidos para o índice de Shannon \& Weaver ( $\mathrm{H}^{\prime}$ ) devem ser utilizados com cautela, uma vez que este índice é calculado no número de espécies e na distribuição do número de indivíduos entre as espécies. O seu valor depende dos critérios de amostragem utilizados nos levantamentos, além da área amostral. MARTINS (1979), com base nos dados de estudos florísticos e fitossociológicos, relatou o índice de diversidade de Shannon e Weaver para várias florestas amazônicas, citando valores que variaram de 3,58 (BASTOS, 1948) a 4,76 (PRANCE et al., 1976). O valor encontrado no presente trabalho foi de 4,20, podendo-se considerar que a mata em estudo apresenta grande riqueza florística.

\section{Estrutura da vegetação}

\section{Diâmetro}

A avaliação da distribuição dos diâmetros de indivíduos arbóreos de uma comunidade, mesmo que apresente problemas para a avaliação das idades, fornece a estrutura de tamanho e de distribuição etária das populações, de grande importância para prediçôes sobre a produção florestal. Neste sentido, a idade real das árvores não é um parâmetro muito importante (HARPER, 1977), e a medição dos diâmetros pode ser usada como uma forma de avaliação das idades (DAUBENMIRE, 1968; HARPER. 1977). SALOMÃO \& ROSA (1989) afirmaram, ainda, que a distribuição em classes diamétricas permite 0 conhecimento do comportamento da espécie.

Procurando verificar a possível existência de periodicidade estacional no crescimento do tronco, MORAES (1970) constatou surtos de crescimento para todos os indivíduos de uma população, quando analisou 21 espécies florestais da Amazônia, indicando que a periodicidade de 
crescimento na maioria dessas espécies não é casual e que indivíduos maiores para uma mesma espécie devem ser considerados mais velhos. Esta interpretação está em desacordo com PIRES (1976), segundo o qual tomando-se a floresta Amazônica como um todo, como uma mistura de espécies, verifica-se que o incremento em grossura do tronco é muito desuniforme, tornando-se impossivel fazer uma estimativa de idade das plantas com base na velocidade de crescimento por classe de circunferência de tronco.

Como pode ser observado na Figura 6, a curva de distribuição dos diâmetros apresenta, em seu aspecto geral, a forma de um "J" invertido, previsível para distribuições balanceadas. Essa é, segundo CARVALHO (1981), a forma geral da distribuição das classes diamétricas das árvores da florestal pluvial amazônica, onde ocorre maior frequiência nas classes de diâmetro menores e, conseqüientemente, menor frequiência nass classes de diâmetro maiores.

Em florestas nativas, quando a razão "q" é constante, significa que há um equilíbrio entre mortalidade e crescimento, ou seja, há $1 \mathrm{~m}$ balancearrento e, quando isto ocorre por um longo período, a estrutura torna-se estabilizadat ou balanceada, com um número proporcional de árvores em cada classe diamétrica (OSMATON, 1968).

Como pode ser observado pela Tabela 2, a razão "q" das sucessivas classes diamétricas, ora aumentam ora diminuem de forma muito irregular. Segundo HEINSDIJK \& BASTOS (1963), na Amazônia a passagem de um determinado grupo de exemplares de uma classe de diâmetro para a imediatamente superior, $10 \mathrm{~cm}$ maior. acarreta a perda, ou a estagnação do crescimento, de metade das plantas. $O$ fato de a mata da Reserva Florestal do Sacavém não apresentar uma razão absolutamente constante está de acordo com HARPER (1977), segrundo o qual, nà prática a maioria das florestas inegulares não apresenta distribuição balanceada mas converge para isso.

As classes de diâmetro são contínuas, o que demonstra que o ciclo de vida das espécies está se completando, uma vez que, segundo DAUBENMIRE (1968), a disposição dos dados em histogramas de frequência nas classes de diametro retratam uma situação atual, podendose anda supor perturbações ocorridas como: incêndios, desmatamentos. baixos índices de germinação e polinização, ataque de pragas é doenças, que se apresentam como intertupções, indicando que o ciclo de vida não estarla se completando, e as espécies. geralmente, não podem ser consideradas como em equilíbrio no ambiente.

O DAP médio de $16.28 \mathrm{~cm}$. encontrado neste trabalho, inferior as encontrados por SALOMÃO \& LISBOA (1988), SALOMÃO (t al. (1988) e SALOMÃO \& ROSA (1989), que foram, respectivamente. de $22,3 \mathrm{~cm}, 21,4 \mathrm{~cm}$ e $31,21 \mathrm{~cm}$. provavelmente é devido à escolha do DAP mínimo, que neste trabalho foi 
de $4,8 \mathrm{~cm}$, enquanto que naqueles estudos foi de $9,55 \mathrm{~cm}$ e $10 \mathrm{~cm}$.

Observando-se as distribuições em classes de DAP das espécies com 10 ou mais indivíduos (Fig. 7), observa-se que apenas Protium heptaphyllum, Cecropia palmata e Coccoloba pichuna apresentaram maior número de indivíduos nas menores classes, embora com ausência das classes superiores, o que pode significar que essas populações estão em crescimento, ou ainda, que estes são o tamanho máximo em DAP que elas atingem, sendo, portanto, espécies de pequeno porte, que não atingem o dossel da mata.

Guarea guidonia, Licania cf. incana, Copaifera langsdorffii, Dipteryx lacunifera, Copaifera officinalis e Maximiliana maripa, por outro lado, são espécies maiores (em altura e DAP), apresentando, de um modo geral, freqüências muito baixas nas classes menores de DAP. o que tanto pode indicar problemas nessas populações para promover uma taxa normal de renovação quanto, que suas sementes e/ou plântulas não encontram condições favoráveis para sua germinação e desenvolvimento.

\section{CARVALHO et al. (1986)} observaram que, sob o ponto de vista sociológico, as espécies presentes em muitas classes de DAP podem ser consideradas as mais importantes para a floresta. Entre as espécies consideradas acima, 4 se encontram distribuídas em apenas 2 classes de DAP, 2 em 3 classes, e 3 espécies em 4 ou mais classes. Licania cf. incana, Guarea guidonia e Dipteryx lacunifera são as espécies melhor distribuídas, ocupando, respectivamente, as primeira, segunda e quarta posições em IVI na mata em estudo.

Assim, com relação à distribuição dos diâmetros para as árvores da Reserva Florestal do Sacavém, pode-se concluir que, apesar das distribuições das espécies mais abundantes não serem, em absoluto, balanceadas, a distribuição geral apresenta-se em forma de "J" invertido, podendo ser considerada como tendendo ao balanceamento.

\section{Altura}

O conceito de estratificação em florestas tropicais tem sido objeto de alguma confusão, sendo mais frequentemente aplicado às alturas das árvores na floresta. Se há picos na curva de distribuição ou se não há árvores em certas classes de altura, então pode-se dizer que a estratificação está presente. No entanto, é necessário decidir se um pico em uma curva é suficientemente distinto para ser chamado de um estrato; além disso, os estratos aparentes dependerão das classes de tamanho escolhidas. A estratificação de altura dos indivíduos e a estratificação do dossel da floresta estão primariamente relacionados à estratificação de espécies e/ou ao padrão de regeneração da floresta (GRUBB et al., 1963). Já HEINSDIJK \& BASTOS (1963) afirmaram que uma das características da floresta tropical pluvial é a maneira pela qual os elementos constitutivos se dispõem 
em altura. Como as árvores são de porte diferentes, alguns autores adotaram classificá-las em estratos e sub-estratos, os quais na realidade praticamente não existem, visto que na grande maioria das vêzes as espécies não fazem parte permanente e definitivamente de um determinado estrato, apenas ficam nele durante um certo tempo. PIRES (1980) também afirmou que a mata é estratificada, considerando as diferentes sinúsias, as adaptações à economia de luz, epifitismos, simbioses, etc., mas não quanto alo aspecto fisionômico, captado pela observação grosseira.

No presente estudo, 58 espécies foram encontradas fazendo parte apenas das classes de altura até $12,0 \mathrm{~m}$ e apresentaram flores e/ou frutos, podendo-se inferir que eram árvores que já tinham atingido sua maturidade sexual, sendo portanto árvores adultas. Outras 23 espécies apresenturamse exclusivamente com alturas superiores a $12,0 \mathrm{~m}$. No aspecto de fisionomia, sendo o dossel irregular e descontínuo, concordase com a afimativa de SCHULZ (1960), PIRES (1981) e SALOMÃO et al. (1988), que dizem que as florestas densas nâo têm copa estratificada.

Observando a distribuição dos indivíduos por classes de altura na Reserva Florestal do Sacavém (Fig. 8), não se percebe claramente nenhum dos tipos de distribuição citados anteriomente, mas sim uma distribuição notavelmente irregular, que se assemelha a uma curva bimodal, com os picos nas classes de 6,0 a $8,0 \mathrm{me}$ de 18,0 a 20,0 m e as diferenças nas classes intermediárias não sendo nuito acentuadas. CAIN \& CASTRO (1959) afimmaram que a estratificação da vegetação na floresta úmida está parcialmente relacionada com a sua estratificação ambiental, sendo que as exigências relativas à radiação solar parecem ser mais importantes que as diferenças de umidade no controle do desenvolvimento da estrutura da floresta.

Considerando a composição florística, as classes acima de $12 \mathrm{~m}$ de altura, com um número menor de indivíduos $(41,46 \%)$ apresentam um número expressivo de espécies $(45,19 \%)$. Isto concorda com as afirmativas de PIRES ct al. (1953) de que existe uma diversidade marcante de espécies arbóreas nas comunidades florestais tropicais, particularmente naquelas da hiléia amazônica. Por outro lado, nas classes até $12 \mathrm{~m}$ de altura, foram amostradas 58 espécies $(55,77 \%$ do total), presentes apenas nessas classes. GENTRY \& EMMONS (1987) afirmaram que o subbosque de uma floresta tropical úmida é composto de um grupo diferente de espécies do dossel, sendo especialmente impontante para a diversidade da floresta. GENTRY \& DODSON (1987) concluíram, ainda, dizendo que as espécies potencialmente arbóreas constituem somente 15 a $22 \%$ da flora de todos os locais neotropicais para os quais flórulas locais estão disponíveis, sendo quase a metade das espécies constituída de ervas, arbustos e pequenas árvores.

A altura média das árvores $(11,16$ m) É menor que a encontrada por SALOMÃO \& LISBOA (1988), SALOMÃO e' al. (1988) e SALOMÃO \& ROSA (1989), que foram, respectivamente, de $16,5 \mathrm{~m}, 17,3$ $\mathrm{m}$ e $18,2 \mathrm{~m}$, e muito aquém da observação feita por DUCKE \& BLACK (1954), 
segundo os quais a altura média das grandes árvores que compõem a abóbada da floresta amazônica pode ser avaliada em 30 a $40 \mathrm{~m}$.

Segundo PIRES (1980), a diminuição do porte das árvores não está obrigatoriamente correlacionada com a diminuição da fertilidade dos solos, embora a escassez de água também não pareça ser a única explicação apropriada. PROCTOR et al.(1983) também afirmam que não há uma relação clara entre a quantidade de nutrientes no solo e a estrutura da floresta, apesar de ser frequientemente assumido que a biomassa está relacionada com o grau de nutrientes no solo.

\section{Bibliografia citada}

ABREU, S.F. 1949. O Estado do Maranhão. Boletin Geográfico, 7(79):743-45.

BALÉE, W. 1986. Análise preliminar de inventário florestal e a etnobotânica Ka'apor (Maranhão). Boletim do Museu Parcuense Emilio Goeldi, Botînica, 2(2):141-167.

.... 1987. A etnobotânica quantitativa dos índios Tembé (Rio Gurupi, Pará). Boletim do Museu Parcıense Emílio Goeldi, Botânica, 3(1):29-50.

BASTOS, A.M. 1948. As matas de Santa Maria do Vila Nova, Territónio do Amapá. Anucirio Brasileiro de Economia Florestal, 1:281188.

BLACK, G.A.; DOBZHANSKY, T,; PAVAN, C. 1950. Some attempts to estimate species diversity and population density of trees in Amazonian forest. Botanical $G a$ zette,111(4):413-425.

BRASIL. Departamento Nacional de Produção Mineral. 1973. Projeto RADAM. Follha SA23 São Luís e parte da Follha SA24 Fortaleza. Rio de Janciro.

BRAUN-BLANQUET, J. 1979. Fitossociologia
- bases para el estudio de las comunidades vegetales. Madrid, H. Blume Ediciones. 440p.

CAIN, S.A.; CASTRO, G.M. de O. 1959. Manual of vegetation analysis. New York, Harper and Brothers Publishers. 325p.

CAIN, S.A.; CASTRO, G.M. de O.; PIRES, J.M.; SILVA, N.T. 1956. Application of some phytosociological techniques to brazilian forests. Ainerican Journal of Botany, 43(10):911-941.

CAMPBELL, D.G., et al. 1986. Quantitative ecological inventory of terra firme and varzea tropical forest on the River Xingu. Brittonia, (38):369-393.

CARVALHO, J.O.P. de. 1981. Distribuição diamétrica de espécies comerciais e potenciais em floresta tropical úmida natural na Amazônia. Boletim de Pesquisa EMBRAPACPATU, (23): 1-34.

-.-- et al. 1986. Composição florística de uma mata secundária no Planalto de Belterra no Pará $l n$ : EMBRAPA/CPATU. Anais do I Simpósio do Trópico únido. EMBRAPAV CPATU, Belém, p.197-205.

CRONQUIST, A. 1981. An integrated system of classification of flowering plants. New York, Columbia University Press. 1262p.

DANTAS, M.; MULLER, N.R.M. 1979. Estudos fito-ecológicos do Trópico úmido brasileiro I. Aspectos fitossociológicos de mata sobre Terra Roxa na região de Altamira, Pará. In: Anais do $30^{\circ}$ Congresso Nacional de Botânica. Sociedade Botânica do Brasil, São Paulo, p.205-218.

-.- - RODRIGUES, I.A.; MULLER, N.R.M. 1980. Estudos fito-ecológicos do Trópico úmido brasileiro Il. Aspectos titossociológicos de mata sobre Latossolo Amarelo em Capitão Poço, Pará. Boletim de Pesquisa, EMBRAPA/CPATU, 9.

DAUBENMIRE, R. 1968. Plant contnunities a textbook of plant synecology. New York, Harper and Row Publishers. 300p.

DUCKE, A:; BLACK, G.A. 1954. Notas sobre a fitogeografía da Amazónia Brasileira. Boletim Técnico do Instituto Agronômico do Norte, 29: 1-62. 
ENGLER, A. 1964. Syllabus der pflanzenfanilien - angiospermen. Berlin, Gebruder Borntraeger. $666 \mathrm{p}$.

FERREIRA, J.R.G. 1992. Estudos floristicos na Reserva Florestal do Sacavém. Mata da Caema, São Luis (Maranhão). Monografia de Bacharelado. Departamento de Biologia, Universidade Federal do Maranhão, São Luís, Maranhāo, 98p.

FRÓES, R. de L. 1953. Limites meridionais e orientais da área de ocorrência da floresta amazônica em território brasileiro. Revista Brasileira de Geografia, 15(1):395.

GENTRY, A.H. 1986. An overview of neotropical phytogeographic patterns with an emphasis on Amazonia. In: EMBRAPA/CPATU. Ancis do I Simpósio do Trópico Úmido. EMBRAPA/CPATU, Belém, p.19-35.

DODSON, C. 1987. Contribution of nontrees to species richness of a tropical rain forest. Biotropica, 19(2):149-156.

- EMMONS, L.H. 1987. Geographical variation in fertility, phenology, and composition of neotropical forests. Biotropica, 19(3):216-227.

GOMES, L.F. 1991. Diversidade e flutuação de populaçóes de abelhas da tribo Euglossini (Hymenoplera, Apidae) em dois ecossistemas de Säo Laís-MA: mata e restinga. Monografia de Bacharelado. Departamento de Biologia, Universidade Federal do Maranhão, São Luis. Maranhão, 60p.

GRUBB, P.J., et al. 1963. A comparison of montane and lowland rain forest in Ecuador $\mathrm{l}$. The forest structure, physiognomy, and floristics. Journal of Ecology, 51:567-601.

GUERRA, I.A.L.T. 1955. Tipos de clima do Nordeste. Revista Brasileira de Geografia, 17(4):63-110.

HARPER, J.L. 1977. Population biology of planls. London, Academic Press. 892p.

HEINSDIJK, D.; BASTOS, A de M. 1963. Inventários florestais na Amazônia.
Boletim do Serviço Florestal, 6:1-100.

HENRIQUES, R.P.B.; SOUSA, E.C.G. de. 1989. Population structure, dispersion and microhabitat regeneration of Carapa guianensis in northeastern Brazil. Biotropica, 21 (3) :204-09.

LISBOA, P.L.B. 1989. Estudo florístico da vegetação arbórea de uma floresta secundária, em Rondônia. Boletim do Muscu Paraense Emílio Goeldi, Botânica. 5(2): 145-162

--- - LISBOA, R.C.L. 1989. Inventários florestais em Rondônia. I. Rodovia Presidente Médici-Costa Marques, Km 90. In: Anais do $35^{\circ}$ Congresso Nacional de Botanica. Sociedade Botannica do Brasil, Manaus.

MACIEL, U.N.; LISBOA, P.L.B. 1989. Estudo florístico de I hectare de mata de terra firme na $\mathrm{Km} 15$ da Rodovia Presidente Médici-Costa Marques (RO-429). Rondônia. Boletim do Museu Paraense Emílio Goeldi, Botânica, 5(1):25-37.

MARTINS, F.R. 1979. O método de quadrantes e a fitossociologia de ama floresta residual do interior do Estado de São Paulo: Parque Estadual do Vassinanga. Tese de Doutorado, Instituto de Biociências, Universidade de Säo Paulo, São Paulo, 239p.

MEYER, H.A. 1952. Structure, growth and drain in balanced uneven-aged forests. Joumal of Forest, 50:85-92.

MORAES, V.H.F. 1970. Periodicidade de crescimento do tronco de árvores da floresta amazônica. Pesquisa Agropecuária Brasileira, 5:315-320.

MORELLATO, L.P.C.; ROSA, N.A. 1991. Caracterização de alguns tipos de vegetação na região amazônica, Serra dos Carajás, Pará, Brasil. Revista Brasileira de Botanica, 14:1-14.

MORI, S.A., ct al. 1989. Composition and structure of an amazonian forest at Camaipi, Amapa, Brazil. Boletim do Museu Parcensé Emílio Goeldi, Botânicia. $5(1): 3-18$.

MOTA, F.S. da. 1986. Meteorologia agricola. 
São Paulo, Nobel. 376 p.

MUELLER-DOMBOIS, D.; ELLENBERG, $\mathrm{H}$. 1974. Aims and methods of vegetation ecology. New York, Willey and Sons. 574p.

OSMATON, H. 1968. The management of forest. Londres, George Allen and Unwin. $384 \mathrm{p}$.

PIRES, J.M. 1976. Aspectos ecológicos da tloresta amazônica. In: Coleção Mossoroense (ed.). Anais do II Congresso Brasileiro de Florestas Tropicais. Mossoró, 65:235-287.

-.-. - 1980. Tipos de vegetação da Amazônia. Vegetalia, 4:1-27.

.... 1981. O conceito de floresta tropical. CVRD Rev., 2(5):17-20.

-..- - DOBZHANSKY, T.; BLACK, G.A. 1953. An estimate of the number of species of trees in an amazonian forest community. Botanical Gazette, 114:467-477.

PRANCE, G.T.; RODRIGUES, W.A.; SILVA, M.F. 1976. Inventário tlorestal de um hectare de mata de terra firme no $\mathrm{Km} 30$ da estrada Manaus-Itacoatiara. Acta Amazonica, 6(1):9-35.

PROCTOR, J. et al. 1983. Ecological studies in four contrasting lowland rain forest in Gunung Mulu National Park, Sarawak I. forest environment, structure and floristics. Joumal of Ecology, 71:237-260.

RIBEIRO, J.R. 1971. O Maranhāo e seu revestimento florístico. Brasil Florestal, 2(5):9-20.

RICHARDS, P.W. 1952. The tropical rain forest: an ecological study. New York, Cambridge University Press. 423p.

RODRIGUES, W.A. 1963. Estudo de 2,6 hectares de mata de terra firme da Serra do Navio, Território do Amapá. Boletim do Museu Paraense Emilio Goeldi, 19:1-44.

SALOMÃO, R. de P.; LISBOA, P.L.B. 1988. Análise ecológica da vegetação de uma floresta pluvial tropical de terra firme, Rondônia. Boletim do Museu Paraense

SALOMĀO, R. de P.; ROSA, N. de A. 1989. Análise da vegetação de floresta pluvial tropical de terra firme, pelo método dos quadrantes: Serra Norte, Carajás, PA. In: Acta Botanica Brasilica (ed.). Anais do $39^{\circ}$ Congresso Nacional de Botânica. Acta Botanica Brasilica, 2(1):27-35. Suplemento.

SALOMÃO, R. de P; SILVA, M.F.F. da; ROSA, N.A. 1988. Inventário ecológico em floresta pluvial tropical de terra firme, Serra Norte, Carajás, Pará. Boletim do Museu Paraense Emílio Goeldi, Botânica, 4(1):1-46.

SCHULZ, J.P. 1960. Ecological studies on rain forest in Northern Suriname. Meded. Bot. Mus. Herb. Rijks., 163:1-267.

SEMATUR. 1992. Plano de Manejo do Parque Estadual do Bacanga. São Luís, Secretaria de Estado do Meio Ambiente e Turismo. $125 p$.

SILVA, M.F.F. da; ROSA, N.A.; SALOMÃO, R. de P. 1986. Estudos botânicos na área do Projeto Ferro Carajás 3. Aspectos florísticos da mata do aeroporto de Serra Norte - PA. Boletin do Museu Paraense Emilio Goeldi. Botânica, 2(2): 169-187.

SILVA, M.F.F da; ROSA, N.A.; OLIVEIRA, J. 1987. Estudos botânicos na área do Projeto Ferro Carajás 5. Aspectos florísticos da mata do Rio Gelado, Pará. Boletim do Museu Paraense Emílio Goeldi, Botânica, 2(1): I-20.

SILVA, M.F.F da; ROSA, N.A. 1989. Análise do estrato arbóreo da vegetação sobre jazidas de cobre na Serra dos Carajás - PA. Boletim do Museu Paraense Emilio Goeldi. Botânica. 5(2):175-206.

SOARES, L. de C. 1953. Evolução dos limites meridionais $\mathrm{e}$ orientais da flora $\mathrm{e}$ vegetação amazônicas em território brasileiro. Revista Brasileira de Geografia, 15(1):101-110. 